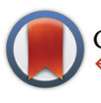

CrossMark \&lick for updates

Cite this: Dalton Trans., 2016, 45, 7131

Received 22nd February 2016 Accepted 15th March 2016 DOI: $10.1039 / c 6 d t 00692 b$ www.rsc.org/dalton

\section{Gyroscope like molecules consisting of trigonal or square planar osmium rotators within three-spoked dibridgehead diphosphine stators: syntheses, substitution reactions, structures, and dynamic properties $\uparrow$}

\author{
Tobias Fiedler, ${ }^{\text {a,b }}$ Nattamai Bhuvanesh, ${ }^{a}$ Frank Hampel, ${ }^{b}$ Joseph H. Reibenspies ${ }^{a}$ and \\ John A. Gladysz*a
}

\begin{abstract}
Reactions of $\left(\mathrm{NH}_{4}\right)_{2} \mathrm{Os} \mathrm{X}_{6}(\mathrm{X}=\mathrm{Cl}, \mathrm{Br})$ with $\mathrm{CO}$ and the phosphines $\mathrm{P}\left(\left(\mathrm{CH}_{2}\right)_{m} \mathrm{CH}=\mathrm{CH}_{2}\right)_{3}(m=6, \mathbf{a} ; 7, \mathbf{b}$; 8, c) give cis,cis,trans-Os $(\mathrm{CO})_{2}(\mathrm{X})_{2}\left(\mathrm{P}\left(\left(\mathrm{CH}_{2}\right)_{m} \mathrm{CH}=\mathrm{CH}_{2}\right)_{3}\right)_{2} \quad(46-73 \%)$. These are treated with Grubbs' catalyst $\left(7 \mathrm{~mol} \%, 0.0010 \mathrm{M}, \mathrm{C}_{6} \mathrm{H}_{5} \mathrm{Cl}\right)$. Subsequent hydrogenations $\left(\mathrm{PtO}_{2}\right)$ yield the gyroscope like complexes cis,cis,trans-Os(CO) $\left(\mathrm{X}_{2}\left(\mathrm{P}\left(\left(\mathrm{CH}_{2}\right)_{n}\right)_{3} \mathrm{P}\right)(n=2 m+2 ; \mathrm{X}=\mathrm{Cl}, 6 \mathrm{a}-\mathrm{c} ; \mathrm{Br}, 7 \mathrm{a}-\mathrm{c} ; 5-31 \%)\right.$ and the isomers

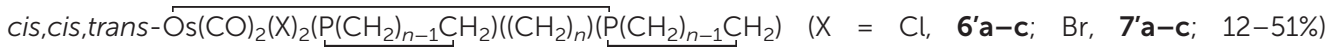
derived from a combination of interligand and intraligand metatheses. Reductions of $\mathbf{6 a}, \mathbf{c}, \mathbf{6} \mathbf{b} \mathbf{b}$, and 7'b with $\mathrm{C}_{8} \mathrm{~K}$ under $\mathrm{CO}$ atmospheres afford trans- $\left.\overline{\mathrm{Os}}(\mathrm{CO})_{3}\left(\mathrm{P}_{(}\left(\mathrm{CH}_{2}\right)_{n}\right)_{3} \mathrm{P}\right)(\mathbf{9 a}, \mathbf{c}, 79-82 \%)$ and trans-




NMR). Preparative reactions of $\mathbf{9 a}, \mathbf{c}$ or $\mathbf{9}^{\prime} \mathbf{b}$ and $\left[\mathrm{H}\left(\mathrm{OEt}_{2}\right)_{2}\right]^{+} \mathrm{BAr}^{-}\left(\mathrm{BAr}_{\mathrm{f}}^{-}=\mathrm{B}\left(3,5-\mathrm{C}_{6} \mathrm{H}_{3}\left(\mathrm{CF}_{3}\right)_{2}\right)_{4}{ }^{-}\right)$afford $9 \mathbf{a}, \mathbf{c}-\mathrm{H}^{+} \mathrm{BAr}_{\mathrm{f}}^{-}(80 \%)$ or $\mathbf{9}^{\prime} \mathbf{b}-\mathrm{H}^{+} \mathrm{BAr}_{\mathrm{f}}^{-}(68 \%)$. Reactions of $\mathbf{6} \mathbf{a}, \mathbf{6}^{\prime} \mathbf{b}$, and $\mathbf{7 a}$ with MeLi or PhLi give cis,cis,trans-

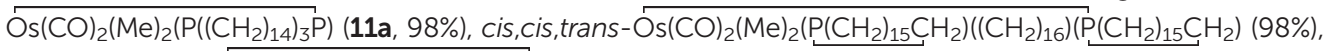
and cis,cis,trans-Os(CO) $)_{2}(\mathrm{Ph})_{2}\left(\mathrm{P}\left(\left(\mathrm{CH}_{2}\right)_{14}\right)_{3} \mathrm{P}\right)(\mathbf{1 2 a}, 58 \%)$. NMR data for $\mathbf{6 a}-\mathrm{c}, 7 \mathrm{a}-\mathrm{c}, \mathbf{9 a}, \mathrm{c}, \mathbf{9 a}, \mathbf{c}-\mathrm{H}^{+} \mathrm{X}^{-}$, and 11a indicate that rotation of the OsLy moieties is fast on the NMR time scale at room temperature. In contrast, the phenyl groups in 12a act as "brakes" and two sets of ${ }^{13} \mathrm{C}$ NMR signals are observed for the methylene chains $(2: 1)$. The crystal structures of $6 a-c, 7 b, c, 7 ' a, 9 a, 9 a-H^{+}$BArf $^{-}, 11 a$, and $12 a$ are analyzed with respect to OsLy rotation in solution and the solid state.
\end{abstract}

\section{Introduction}

Macroscopic gyroscopes have played key roles in numerous technologies over the last century, but consumer consciousness was elevated when Steve Jobs rolled out the iPhone against a backdrop of a classical toy gyroscope, and touted an interface to an accelerometer to provide the six axis motion sensing that is essential to so many applications. ${ }^{1}$ Accordingly, there are many

\footnotetext{
${ }^{a}$ Department of Chemistry, Texas A\&M University, PO Box 30012, College Station, Texas 77842-3012, USA. E-mail: gladysz@mail.chem.tamu.edu

${ }^{b}$ Institut für Organische Chemie and Interdisciplinary Center for Molecular Materials, Friedrich-Alexander-Universität Erlangen-Nürnberg, Henkestraße 42, 91054 Erlangen, Germany

$\dagger$ Electronic supplementary information (ESI) available: Experimental procedures, representative spectra, tables of characterization data. CCDC 1446694-1446703. For ESI and crystallographic data in CIF or other electronic format see DOI: 10.1039/c6dt00692b
}

objectives driving the miniaturization of gyroscopes, and all of the underlying physics remains in force at the molecular level. ${ }^{2}$ Although the term "gyroscope" has been applied rather loosely to molecules, ${ }^{3}$ only a few investigators have been actively trying to engineer working devices. ${ }^{4-6}$ A common denominator among these efforts has been the construction of cage like housings, often termed "stators", which shield the rotating moieties or "rotators" from their surroundings.

As shown in Scheme 1, we have discovered that three fold intramolecular and interligand ring closing alkene metatheses of trans bis(phosphine) complexes of the type I can be effected in surprisingly high yields. ${ }^{7-12}$ This methodology has been used to access square planar, trigonal bipyramidal, and octahedral complexes, as detailed in earlier reports. Since mixtures of $Z / E \mathrm{C}=\mathrm{C}$ isomers are commonly obtained, hydrogenations are subsequently effected, giving homogeneous samples featuring cage like trans spanning dibridgehead diphosphines that encapsulate the remaining ligands (II). Analogous routes 


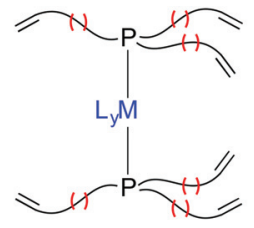

I

$(\mathrm{l})=\left(\mathrm{CH}_{2}\right)_{m}$

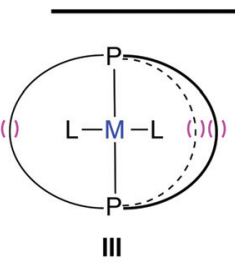

$\mathrm{M}=\operatorname{Pd}(\mathrm{II}), \operatorname{Pt}(\mathrm{II}), \operatorname{Rh}(\mathrm{I})$ $n=14,16,18$
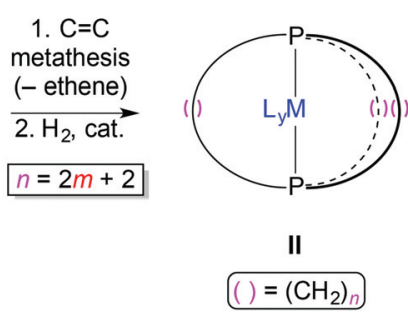

II
Scheme 1 General syntheses of gyroscope like complexes with different coordination geometries.

have been used to prepare conceptually related trans bis(pyridine) complexes in which the ortho or meta carbon atoms are tethered by two connecting bridges. ${ }^{13}$

Many properties of II can be correlated to the coordination geometry. Earlier, we briefly communicated syntheses, structures, and substitution reactions of some octahedral rhenium(I) complexes with rotators of the formula $\operatorname{Re}(\mathrm{CO})_{3}(\mathrm{X})(\mathbf{V} ; \mathrm{X}=$ $\mathrm{Cl}, \mathrm{Br}) .{ }^{11}$ In this full paper, no part of which has been previously disclosed, we describe related efforts with octahedral osmium(II) and trigonal bipyramidal osmium(0) complexes. The effectiveness of the three-fold interligand ring closing metathesis is studied as a function of macrocycle size. The feasibility of addition, substitution, and reduction reactions within the diphosphine cages is then demonstrated. The sizes of the ligands are varied to probe rotational dynamics within the cage. A number of crystal structures are determined that provide insight, and define constraints on rotation in the solid state. Additional related results have been detailed elsewhere. ${ }^{14}$

\section{Results}

\section{Ring closing metatheses of octahedral osmium(II) complexes}

Treatment of the readily available hexabromoosmate(Iv) salt $\left(\mathrm{NH}_{4}\right)_{2} \mathrm{OsBr}_{6}{ }^{15 a}$ with $\mathrm{CO}$ and then $\mathrm{PPh}_{3}$ has been shown to give the osmium(II) bis(phosphine) complex cis,cis,trans$\mathrm{Os}(\mathrm{CO})_{2}(\mathrm{Br})_{2}\left(\mathrm{PPh}_{3}\right)_{2},{ }^{16}$ in which the phosphine ligands are trans. ${ }^{17}$ Accordingly, the hexachloride and hexabromide complexes $\left(\mathrm{NH}_{4}\right)_{2} \mathrm{OsX}_{6}{ }^{15}$ were suspended in 2-methoxyethanol and heated under $\mathrm{CO}$ (10 bar) to give light yellow solutions. Subsequent additions of the alkene containing phosphines $\mathrm{P}\left(\left(\mathrm{CH}_{2}\right)_{m} \mathrm{CH}=\mathrm{CH}_{2}\right)_{3}(m=6, \mathbf{1 a} ; 7, \mathbf{1 b} ; 8, \mathbf{1 c})^{18}$ gave, as depicted in Scheme 2, the bis(phosphine) complexes cis,cis,trans$\mathrm{Os}(\mathrm{CO})_{2}(\mathrm{X})_{2}\left(\mathrm{P}\left(\left(\mathrm{CH}_{2}\right)_{m} \mathrm{CH}=\mathrm{CH}_{2}\right)_{3}\right)_{2}(\mathrm{X}=\mathrm{Cl}, \mathbf{2 a}-\mathbf{c} ; \mathrm{X}=\mathrm{Br}, \mathbf{3 a}-\mathbf{c})$ as yellow oils in $46-73 \%$ yields after chromatographic workups. $^{19}$
All new complexes were characterized by NMR $\left({ }^{1} \mathrm{H},{ }^{13} \mathrm{C}\left\{{ }^{1} \mathrm{H}\right\}\right.$, $\left.{ }^{31} \mathrm{P}\left\{{ }^{1} \mathrm{H}\right\}\right)$ and IR spectroscopy, mass spectrometry, and microanalysis, as summarized in the ESI. $\dagger$ The most diagnostic NMR and IR data are provided in Table 1. The $\mathrm{PC}_{2} \underline{\mathrm{CH}}_{2} \underline{\mathrm{C}}_{2}$ ${ }^{1} \mathrm{H}$ NMR signals were assigned using ${ }^{1} \mathrm{H},{ }^{1} \mathrm{H}$ COSY $2 \mathrm{D}$ NMR spectra. The $\mathrm{P}_{\vec{C}} \mathrm{H}_{2} \underline{\mathrm{C}} \mathrm{H}_{2} \underline{\mathrm{C}} \mathrm{H}_{2}{ }^{13} \mathrm{C}$ NMR signals could in turn be assigned by ${ }^{1} \overline{\mathrm{H}},{ }^{13} \mathrm{C}\left\{{ }^{1} \mathrm{H}\right\}$ gHMQC spectra, per the example in Fig. 1. The $\mathrm{PCH}_{2}$ and $\mathrm{PCH}_{2} \mathrm{CH}_{2} \underline{C H}_{2}$ signals were phosphorus coupled virtual triplets $\left({ }^{1} J_{\mathrm{CP}}=15.5-15.9 \mathrm{~Hz}\right.$ and ${ }^{3} J_{\mathrm{CP}}=6.3-6.4 \mathrm{~Hz}$, respectively), ${ }^{20}$ whereas the $\mathrm{PCH}_{2} \underline{C} \mathrm{H}_{2}$ signals were singlets ( $y$ axis, Fig. 1). The CO ligands gave triplets due to coupling to two equivalent phosphorus atoms $\left({ }^{2} J_{\mathrm{CP}}=7.2-7.5 \mathrm{~Hz}\right)$. Representative ${ }^{1} \mathrm{H}$ NMR spectra are provided in the ESI (see Fig. s1† and the $x$ axis, Fig. 1).

The IR spectra of $2 \mathbf{a}-\mathbf{c}$ and $3 \mathbf{a}-\mathbf{c}$ showed two $\nu_{\mathrm{CO}}$ bands at 2019-2023 $\mathrm{cm}^{-1}$ and 1945-1949 $\mathrm{cm}^{-1}$ (Table 1), consistent with cis CO ligands and comparable to literature values for related complexes. ${ }^{16,21}$ If the CO ligands were trans, only a single IR band would be expected. As shown in Scheme 2, the reference compound cis,cis,trans-Os $(\mathrm{CO})_{2}(\mathrm{Br})_{2}\left(\mathrm{P}\left(n-\mathrm{C}_{8} \mathrm{H}_{17}\right)_{3}\right)_{2}$ (8a) was isolated in $85 \%$ yield following the hydrogenation of the dibromide complex $3 \mathrm{a}$. As given in Table 1 , the $\nu_{\mathrm{CO}}$ values, ${ }^{13} \mathrm{C}$ NMR chemical shifts and $J_{\mathrm{CP}}$ values, and ${ }^{31} \mathrm{P} \mathrm{NMR}$ chemical shift were very close to those of $\mathbf{2 a - c}$ and $3 \mathbf{a}-\mathbf{c}$.

As shown in Scheme 2, dilute chlorobenzene solutions of 2a-c and 3a-c $(0.0010 \mathrm{M})$ were treated with Grubbs' first generation catalyst (7.0-7.5 mol\%). To help remove the ethene byproduct, the mixtures were aspirated with a slow stream of nitrogen. Aliquots were analyzed by ${ }^{1} \mathrm{H} \mathrm{NMR}$, and representative spectra are shown in the ESI (Fig. s2 $\dagger$ ). In all cases, the two $\mathrm{CH}=\mathrm{CH}_{2}$ multiplets were replaced by new $\mathrm{CH}=\mathrm{CH}$ signals with intermediate chemical shifts (mixtures of $E / Z$ isomers). The patterns for $\mathbf{2} \mathbf{b}$ and $\mathbf{3} \mathbf{b}$ differed from those of $\mathbf{2} \mathbf{a}, \mathbf{c}$ and $\mathbf{3 a} \mathbf{a}, \mathbf{c}$ reflecting differing product distributions as described below.

After the starting materials could no longer be detected, the mixtures were aspirated with air and filtered through $\mathrm{Al}_{2} \mathrm{O}_{3}$ to remove ruthenium residues. Incomplete catalyst oxidation or removal seemed to increase the amount of insoluble polymeric material upon concentration. The crude metathesis products, denoted $\mathbf{4}^{*} \mathbf{a}-\mathbf{c}$ and $\mathbf{5}^{*} \mathbf{a}-\mathbf{c}$, were isolated as light brown sticky oils. The major components of those mixtures were, as inferred from purified derivatives below and shown in Scheme 2, either the gyroscope like complexes cis, cis, trans- $\mathrm{Os}(\mathrm{CO})_{2}(\mathrm{X})_{2}\left(\mathrm{P}\left(\left(\mathrm{CH}_{2}\right)_{m} \mathrm{CH}=\mathrm{CH}\left(\mathrm{CH}_{2}\right)_{m}\right)_{3} \mathrm{P}\right.$ $(\mathbf{4 a}, \mathbf{c}$ and $\mathbf{5 a}, \mathbf{c})$ or isomeric species cis,cis,trans$\mathrm{Os}(\mathrm{CO})_{2}(\mathrm{X})_{2}\left(\mathrm{P}\left(\mathrm{CH}_{2}\right)_{m} \mathrm{CH}=\mathrm{CH}\left(\mathrm{CH}_{2}\right)_{m-1} \mathrm{CH}_{2}\right)\left(\left(\mathrm{CH}_{2}\right)_{m} \mathrm{CH}=\right.$ $\left.\left.\mathrm{CH}\left(\mathrm{CH}_{2}\right)_{m}\right)\left(\mathrm{PCH}_{2}\right)_{m} \mathrm{CH}=\mathrm{CH}\left(\mathrm{CH}_{2}\right)_{m-1} \mathrm{CH}_{2}\right) \quad\left(4^{\prime} \mathbf{b}\right.$ and $\left.5^{\prime} \mathbf{b}\right)$. The former are derived by interligand metatheses, and the latter by combinations of intraligand and interligand metatheses. These mixtures were characterized by ${ }^{1} \mathrm{H}$ and ${ }^{31} \mathrm{P}$ NMR (Experimental section) and no attempts were made to separate the various products. For $\mathbf{4 a}-\mathbf{c}$ and $\mathbf{5 a}-\mathbf{c}$, four $\mathrm{C}=\mathrm{C}$ isomers are possible (EEE, EEZ, EZZ, ZZZ), and for $\mathbf{4}^{\prime} \mathbf{a}-\mathbf{c}$ and $\mathbf{5}$ 'a-c, six $\mathrm{C}=\mathrm{C}$ isomers are possible $(Z E E, Z E Z, Z Z Z, E E E, E E Z, E Z Z$; the first letter designates the interligand linkage). Hence, as many as ten ${ }^{31} \mathrm{P}$ NMR signals may be present. 


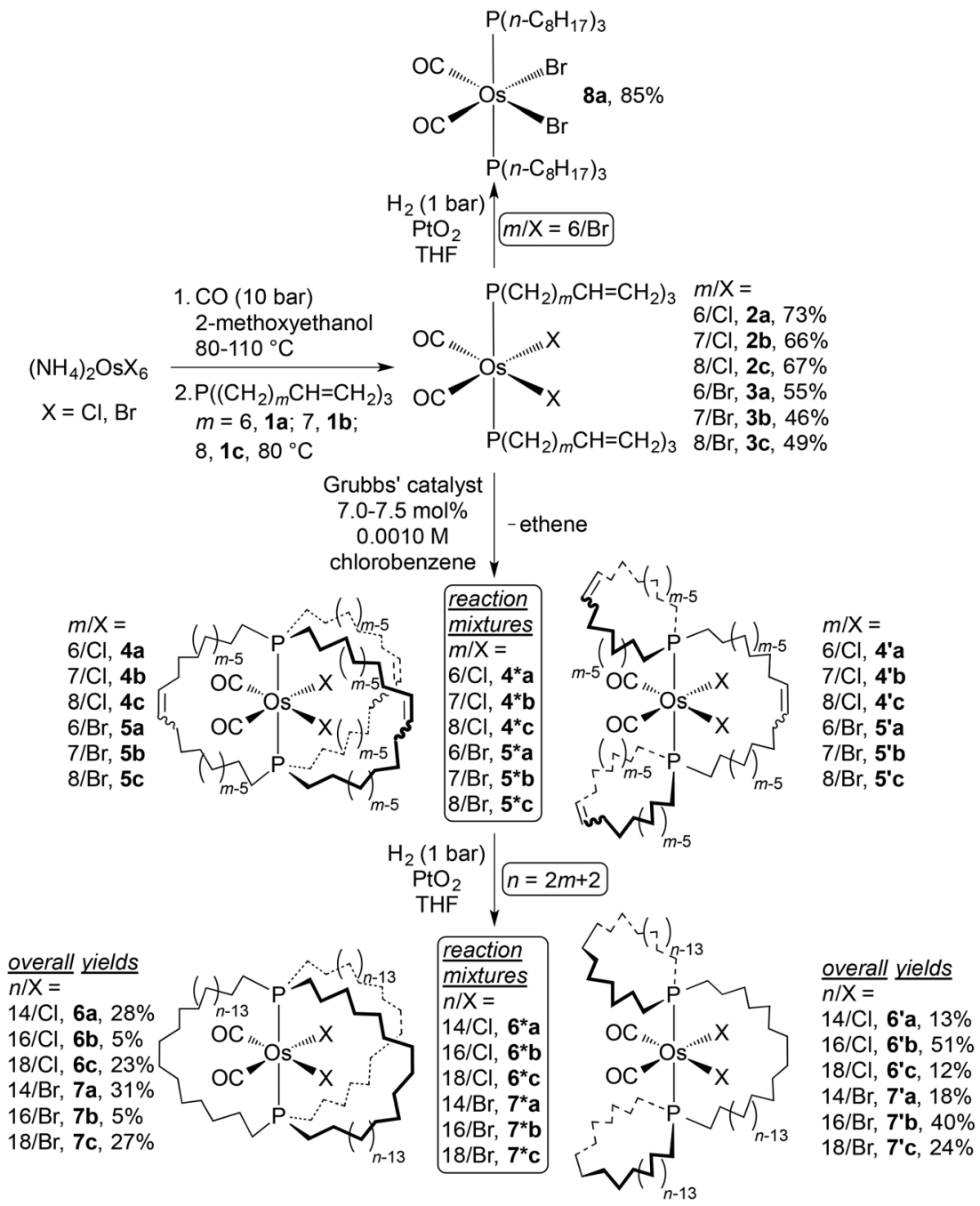

Scheme 2 Syntheses and three fold ring closing alkene metatheses of osmium complexes $2 a-c$ and $3 a-c$.



Fig. 1 Partial ${ }^{1} \mathrm{H}^{13} \mathrm{C}\left\{{ }^{1} \mathrm{H}\right\}$ gHMQC NMR spectrum $(500 \mathrm{MHz})$ of 3a illustrating signal assignments and virtual triplets for complexes of the formula cis, cis, trans- $\mathrm{Os}(\mathrm{CO})_{2}(\mathrm{X})_{2}\left(\mathrm{P}\left(\left(\mathrm{CH}_{2}\right)_{m} \mathrm{CH}=\mathrm{CH}_{2}\right)_{3}\right)_{2}$.

THF solutions of $\mathbf{4}^{*} \mathbf{a}-\mathbf{c}$ and $5^{*} \mathbf{a}-\mathbf{c}$ were then stirred under $\mathrm{H}_{2}$ (balloon pressure) in the presence of $\mathrm{PtO}_{2}$ (1017 mol\%). Aliquots were assayed by ${ }^{1} \mathrm{H}$ NMR until the
$\mathrm{CH}=\mathrm{CH}$ signals were no longer detected. Chromatographic workups afforded two series of isomeric products as shown in Scheme 2. The gyroscope like complexes cis,cis,trans$\mathrm{Os}(\mathrm{CO})_{2}(\mathrm{X})_{2}\left(\mathrm{P}\left(\left(\mathrm{CH}_{2}\right)_{n}\right)_{3} \mathrm{P}\right)(\mathrm{X}=\mathrm{Cl}, \mathbf{6 a}-\mathbf{c} ; \mathrm{Br}, 7 \mathbf{a}-\mathbf{c})$ were obtained in $5-31 \%$ overall yields from $2 \mathbf{a}-\mathbf{c}$ or $3 \mathbf{a}-\mathbf{c}$. The new index $n$, indicating the number of consecutive methylene groups, corresponds to $2 m+2$. The isomeric complexes cis,cis,trans$\mathrm{Os}(\mathrm{CO})_{2}(\mathrm{X})_{2}\left(\mathrm{P}\left(\mathrm{CH}_{2}\right)_{n-1} \mathrm{CH}_{2}\right)\left(\left(\mathrm{CH}_{2}\right)_{n}\right)\left(\mathrm{P}\left(\mathrm{CH}_{2}\right)_{n-1} \mathrm{CH}_{2}\right)(\mathrm{X}=\mathrm{Cl}, \mathbf{6}$ 'a-c; $\left.\mathrm{Br}, \mathbf{7}^{\prime} \mathbf{a}-\mathbf{c}\right)$ were obtained in $12-51 \%$ yields. These are comprised of two phosphacycles (from intraligand metatheses; ring size $n+1$ ) and one diphosphaosmacycle (from interligand metathesis; ring size $n+3)$.

Key characterization data for $\mathbf{6 a}-\mathbf{c}, \mathbf{7} \mathbf{a}-\mathbf{c}, \mathbf{6}^{\prime} \mathbf{a}-\mathbf{c}$, and $\mathbf{7}^{\prime} \mathbf{a}-\mathbf{c}$ are summarized in Tables 1 and s1. $\uparrow$ The ${ }^{1} \mathrm{H}$ and ${ }^{13} \mathrm{C}$ NMR spectra of the gyroscope like complexes $\mathbf{6 a - c}$ and $7 \mathbf{a}-\mathbf{c}$ were relatively simple, with $\underline{\mathrm{PCH}}_{2} \underline{\mathrm{CH}}_{2} \underline{\mathrm{CH}}_{2}$ and $\mathrm{CO}$ chemical shifts and coupling constants similar to those of the acyclic precursors $2 \mathrm{a}-\mathbf{c}$ and 3a-c (Table 1 ), and a total of $n / 2$ methylene ${ }^{13} \mathrm{C}$ signals. Representative ${ }^{1} \mathrm{H}$ and ${ }^{13} \mathrm{C}$ NMR spectra are provided in the ESI (Fig. s3 and s4†). 
Table 1 Selected NMR data for osmium complexes



${ }^{a}$ All signals for which $J$ values are given correspond to triplets. ${ }^{b}$ Oil or powder film. ${ }^{c}$ NMR spectra were recorded in $\mathrm{C}_{6} \mathrm{D}_{6} \cdot{ }^{d}$ These two signals overlap, such that one of the outer peaks of the triplet is obscured. The coupling constant is derived from the two peaks of the triplet that are visible. ${ }^{e}$ Approximate intensity ratio $1: 2 .{ }^{f}$ These two signals overlap, but the outer peaks of the virtual triplet are visible on each side of a broadened central peak. ${ }^{g}$ These two virtual triplets overlap, but at least two peaks of each are distinguishable. ${ }^{h}$ These two virtual triplets overlap, but all six peaks are distinguishable. ${ }^{i}$ NMR spectra were recorded in $\mathrm{CDCl}_{3} .{ }^{j}$ Approximate intensity ratio $2: 1 .{ }^{k}$ Not recorded. ${ }^{l}$ These three triplets overlap with other signals and the chemical shifts and coupling constants could not be unambiguously assigned.

The $\underline{\mathrm{CCH}}_{2} \underline{\mathrm{CH}}_{2} \underline{\mathrm{CH}}_{2}{ }^{1} \mathrm{H}$ and ${ }^{13} \mathrm{C}$ NMR signals of $\mathbf{6}^{\prime} \mathbf{a}-\mathbf{c}$ and $7^{\prime}$ a-c (Table 1) could be assigned using ${ }^{1} \mathrm{H},{ }^{1} \mathrm{H}$ COSY and ${ }^{1} \mathrm{H},{ }^{13} \mathrm{C}\left\{{ }^{1} \mathrm{H}\right\}$ gHMQC or $g$ HSQC techniques. The spectra were more complex than those of the gyroscope like compounds $\mathbf{6 a - c}$ and $7 \mathbf{a}-\mathbf{c}$, in part due to the greater numbers of inequivalent methylene groups, making for $n{ }^{13} \mathrm{C}$ signals, with the intensities of half roughly twice those of the others (see Fig. s $4 \dagger$ ). Furthermore, the protons of each methylene group of the phosphacycles are now diastereotopic. In the representative case of $7^{\prime} \mathbf{b}$, the $\mathrm{PCHH}^{\prime}$ signals exhibited quite different chemical shifts (2.47 and $2.20 \mathrm{ppm})$, both downfield of the $\mathrm{PCH}_{2}$ signal associated with the diphosphaosmacycle $(2.02 \mathrm{ppm})$. The $\mathrm{PCHH}^{\prime} \mathrm{CH}{ }^{\prime}$ protons also exhibited quite different chemical shifts (1.70 and $1.37 \mathrm{ppm})$, but these overlapped with other methylene signals and could only be assigned via 2D techniques (see Fig. s5 and s6†). The ${ }^{31} \mathrm{P}$ NMR chemical shifts of $\mathbf{6}^{\prime} \mathbf{a}-\mathbf{c}$ and 7 'a-c were always slightly downfield of the gyroscope like analogs (Table 1).

The thermal behavior of the new complexes was investigated as summarized in Table s1 (ESI $\dagger$ ). The melting points of the gyroscope like complexes $\mathbf{6 a}-\mathbf{c}$ and $7 \mathbf{a}-\mathbf{c}$ were significantly 
higher than those of the isomers 6'a-c and 7'a-c (e.g., $199{ }^{\circ} \mathbf{C}$ for $7 \mathbf{b}$ vs. $54{ }^{\circ} \mathrm{C}$ for $\left.7^{\prime} \mathbf{b}\right)$. Only three of the latter were solids; the others were sticky oils. The melting points decreased with methylene chain lengths. TGA measurements showed no mass losses below $255{ }^{\circ} \mathbf{C}$. With $6 \mathbf{6 a}, \mathbf{b}$ and $7 \mathbf{a}$, DSC measurements revealed additional endotherms at temperatures below the melting endotherms, suggestive of phase transitions.

The gyroscope like complex with the shortest methylene chain $\left(\left(\mathrm{CH}_{2}\right)_{14}\right)$ and the largest ligands (bromide), 7a, was analyzed by variable temperature ${ }^{13} \mathrm{C}$ NMR. Spectra were recorded in $10-20{ }^{\circ} \mathrm{C}$ intervals between 20 and $-100{ }^{\circ} \mathrm{C}$ in $\mathrm{CD}_{2} \mathrm{Cl}_{2}$ (see Fig. $\mathrm{s} 7 \dagger$ ). Seven signals were detected at room temperature, consistent with rapid rotation of the $\mathrm{Os}(\mathrm{CO})_{2}(\mathrm{Br})_{2}$ moiety. At lower temperatures no decoalescence - only line broadening and some loss of intensity - was observed. Thus, $\mathrm{Os}(\mathrm{CO})_{2}(\mathrm{Br})_{2}$ rotation remains fast on the NMR time scale at low temperatures. Since the $\mathrm{CO}{ }^{13} \mathrm{C}$ NMR signal exhibits phosphorus coupling, this eliminates the possibility of $\mathrm{CO}$ or diphosphine dissociation in the process that renders the methylene chains equivalent.

\section{Trigonal bipyramidal osmium(0) complexes}

As represented in Scheme 1, a family of trigonal bipyramidal, $\mathrm{Fe}(\mathrm{CO})_{3}$ based gyroscope like complexes has been previously reported. ${ }^{7}$ We sought to access analogous osmium(0) species. The first complex of the formula trans-Os(CO) $)_{3}\left(\mathrm{PR}_{3}\right)_{2}$ was described by Collman and Roper. ${ }^{16}$ It was prepared by reduction of the osmium(II) complex cis,cis,trans-
$\mathrm{Os}(\mathrm{CO})_{2}(\mathrm{Br})_{2}\left(\mathrm{PPh}_{3}\right)_{2}$ with zinc under $\mathrm{CO}(4-5$ bar $)$ in DMF at $140{ }^{\circ} \mathrm{C}$. In order to avoid these harsh conditions, two alternative reducing agents were tested. The first, potassium graphite $\left(\mathrm{C}_{8} \mathrm{~K}\right){ }^{22}$ was heterogeneous, and had already been used to reduce other osmium(II) complexes; ${ }^{21}$ the second was a strong homogeneous ditungsten(II) reductant, $\mathrm{W}_{2}(\mathrm{hpp})_{4},{ }^{23}$ where hpp is a bridging anionic donor of the type $\mathrm{R}^{\prime} \mathrm{N} \cdots \mathrm{C}\left(\mathrm{NR}_{2}\right) \cdots \mathrm{NR}^{\prime}$.

As shown in Scheme 3, THF suspensions of $\mathrm{C}_{8} \mathrm{~K}$ (20-30 equiv.) were added to CO saturated solutions of the chloride and bromide substituted gyroscope like complexes $\mathbf{6 a}$ and $7 \mathbf{a}, \mathbf{c}$, as well as $\mathbf{6}^{\prime} \mathbf{b}$ and $7^{\prime} \mathbf{b}$. The mixtures were aspirated with a slow stream of $\mathrm{CO}$ at room temperature. Conversions were monitored by ${ }^{31} \mathrm{P}$ NMR or IR spectroscopy (see Fig. s8 $\dagger$ ). The bromide complexes were reduced significantly faster than the chloride complexes ( $c a .1 \mathrm{~h} v s$. overnight). In each case, the product ${ }^{31} \mathrm{P}$ NMR signal was downfield from that of the starting material. The IR $\nu_{\mathrm{CO}}$ bands of the starting materials were replaced by a single absorption at lower frequencies, indicative of enhanced backbonding.

Workups gave the target complexes trans$\widehat{\mathrm{Os}}(\mathrm{CO})_{3}\left(\mathrm{P}\left(\left(\mathrm{CH}_{2}\right)_{n}\right)_{3} \mathrm{P}\right)(\mathbf{9 a}, \mathrm{c})$ in $79-82 \%$ yields, and the phosphacycle containing species trans-Os $(\mathrm{CO})_{3}\left(\mathrm{P}\left(\mathrm{CH}_{2}\right)_{15} \mathrm{CH}_{2}\right)\left(\left(\mathrm{CH}_{2}\right)_{16}\right)\left(\mathrm{P}\left(\mathrm{CH}_{2}\right)_{15} \mathrm{CH}_{2}\right)$ $\left(\mathbf{9}^{\prime} \mathbf{b}\right)$ in $53-84 \%$ yields, all as white solids. A model complex with two acyclic trialkylphosphine ligands, cis,cis,trans-Os $(\mathrm{CO})_{3}\left(\mathrm{P}\left(n-\mathrm{C}_{8} \mathrm{H}_{17}\right)_{3}\right)_{2} \quad$ (10a), was similarly prepared in $85 \%$ yield from $8 \mathbf{a}$ (Scheme 2). The spectroscopic data, summarized in Table 1, exhibited several trends in addition to those noted above. The CO ligand ${ }^{13} \mathrm{C}$ NMR signals shifted 22.3-23.7 ppm downfield from those of the osmium(II) complexes to $197.5-198.8 \mathrm{ppm}$, and the ${ }^{2} J_{\mathrm{CP}}$ values increased

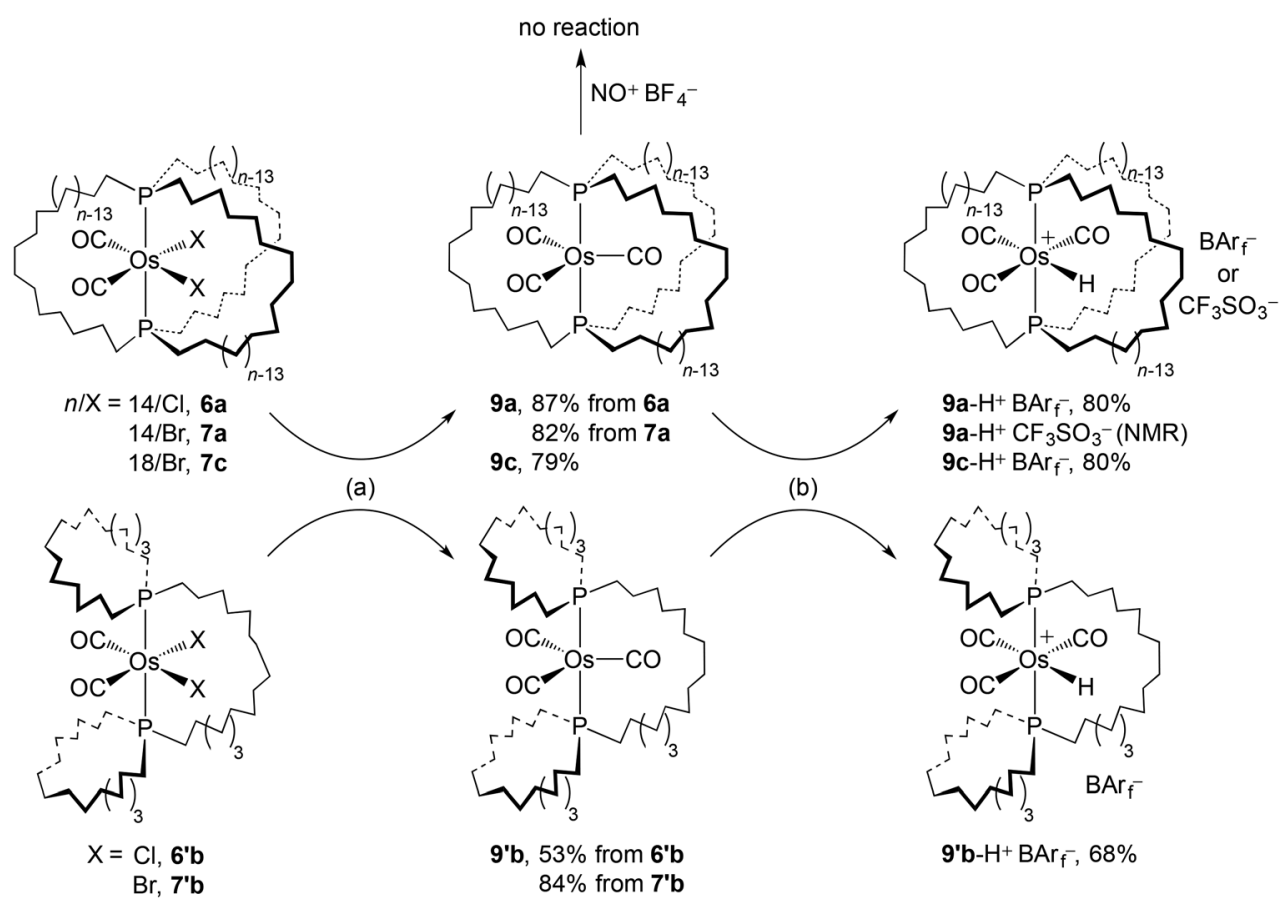

Scheme 3 Syntheses of the osmium(0) complexes $9 a, c$ and 9'b and their protonation: (a) $\mathrm{C}_{8} \mathrm{~K}, \mathrm{CO}, \mathrm{THF}^{\prime}(\mathrm{b})\left[\mathrm{H}\left(\mathrm{OEt}_{2}\right)_{2}\right]^{+} \mathrm{BAr}_{\mathrm{f}}{ }^{-} / \mathrm{CH}_{2} \mathrm{Cl}_{2}$ or $\mathrm{CF}_{3} \mathrm{SO}_{3} \mathrm{H} /$ $\mathrm{CDCl}_{3}$. 
(11.8-12.2 vs. 7.2-7.6 Hz). The $\mathrm{PCH}_{2}$ signals $\left({ }^{1} J_{\mathrm{CP}}=16.6-17.4 \mathrm{~Hz}\right)$ shifted 4.2-6.4 ppm downfield from the osmium(II) complexes, but the other methylene signals were comparable.

The reaction of $\mathbf{6 a}$ and $\mathrm{W}_{2}(\mathrm{hpp})_{4}$ (ca. 5 equiv.) was investigated under similar conditions. However, workup gave 9a in only $23 \%$ yield. Hence, this method was not pursued further, and additional details are provided elsewhere. ${ }^{14}$ Complex 9a would also very likely be available via metathesis of the trigonal bipyramidal complex trans-Os $(\mathrm{CO})_{3}\left(\mathrm{P}\left(\left(\mathrm{CH}_{2}\right)_{m} \mathrm{CH}=\mathrm{CH}_{2}\right)_{3}\right)_{2}$, but this precursor proved difficult to synthesize in pure form.

\section{Protonation reactions}

The next objective was to modify the rotators in the gyroscope like complexes. Osmium tricarbonyl complexes of the type trans-Os $(\mathrm{CO})_{3}\left(\mathrm{PR}_{3}\right)_{2}$ are readily protonated by a variety of strong acids to yield cationic metal hydrides of the formula mer,trans $-\left[\mathrm{Os}(\mathrm{H})(\mathrm{CO})_{3}\left(\mathrm{PR}_{3}\right)_{2}\right]^{+} \mathrm{X}^{-} \cdot{ }^{24}$ As a test reaction, $\mathrm{CF}_{3} \mathrm{SO}_{3} \mathrm{H}$ was added to a solution of 9a in $\mathrm{CDCl}_{3}$ in a NMR tube (Scheme 3). $\mathrm{A}^{1} \mathrm{H}$ NMR spectrum showed the quantitative generation of the target complex mer,trans- $\left[\overparen{\mathrm{Os}(\mathrm{H})(\mathrm{CO})_{3}\left(\mathrm{P}\left(\left(\mathrm{CH}_{2}\right)_{14}\right)_{3} \mathrm{P}\right)}\right]^{+} \mathrm{CF}_{3} \mathrm{SO}_{3}{ }^{-}$ $\left(9 \mathrm{a}-\mathrm{H}^{+} \mathrm{CF}_{3} \mathrm{SO}_{3}{ }^{-}\right)$. The hydride signal appeared at $-8.50 \mathrm{ppm}$ as a phosphorus coupled triplet $\left(J_{\mathrm{HP}}=15.3 \mathrm{~Hz}\right)$. The ${ }^{13} \mathrm{C} \mathrm{NMR}$ spectrum showed seven methylene signals and two triplets for the carbonyl groups cis and trans to the hydride ligand (intensity 2:1). Partial ${ }^{1} \mathrm{H}$ and ${ }^{13} \mathrm{C}$ NMR spectra are illustrated in Fig. s9. $\dagger$ However, attempts to isolate $9 \mathrm{a}-\mathrm{H}^{+} \mathrm{CF}_{3} \mathrm{SO}_{3}{ }^{-}$as a solid were unsuccessful.

In hopes of obtaining crystalline hydride complexes, $\mathrm{BAr}_{\mathrm{f}}{ }^{-}$salts were sought $\left(\mathrm{BAr}_{\mathrm{f}}^{-}=\mathrm{B}\left(3,5-\mathrm{C}_{6} \mathrm{H}_{3}\left(\mathrm{CF}_{3}\right)_{2}\right)_{4}{ }^{-}\right)$. Thus, $\mathrm{CH}_{2} \mathrm{Cl}_{2}$ solutions of $\mathbf{9 a , c}$ as well as $\mathbf{9}^{\prime} \mathbf{b}$ were treated with the proton containing oxonium salt $\left[\mathrm{H}\left(\mathrm{OEt}_{2}\right)_{2}\right]^{+} \mathrm{BAr}_{\mathrm{f}}{ }^{-}$(1 equiv.). ${ }^{25}$ As shown in Scheme 3, workups gave the gyroscope like hydride complexes $\mathbf{9 a}, \mathbf{c}-\mathrm{H}^{+} \quad \mathrm{BAr}_{\mathrm{f}}^{-}$as well as mer,trans$\left[\mathrm{Os}(\mathrm{H})(\mathrm{CO})_{3}\left(\mathrm{P}\left(\mathrm{CH}_{2}\right)_{15} \mathrm{CH}_{2}\right)\left(\left(\mathrm{CH}_{2}\right)_{16}\right)\left(\mathrm{P}\left(\mathrm{CH}_{2}\right)_{15} \mathrm{CH}_{2}\right)\right]^{+} \mathrm{BAr}_{\mathrm{f}}{ }^{-}$ $\left(\mathbf{9}^{\prime} \mathbf{b}-\mathrm{H}^{+} \mathrm{BAr}_{\mathrm{f}}^{-}\right)$in $68-80 \%$ yields. The complex $\mathbf{9 a}-\mathrm{H}^{+} \mathrm{BAr}_{\mathrm{f}}^{-}$was obtained as a white powder that could be crystallized, and the others as yellow gums.

Characteristic data are presented in Table 1 . The hydride ${ }^{1} \mathrm{H}$ NMR signals were similar to that of $9 \mathrm{a}-\mathrm{H}^{+} \mathrm{CF}_{3} \mathrm{SO}_{3}{ }^{-}$, and two $\mathrm{CO}{ }^{13} \mathrm{C}$ NMR signals were observed $(2: 1)$. The ${ }^{31} \mathrm{P}$ NMR signals were 7.6-8.2 ppm upfield from those of the precursors. As exemplified in Fig. s10, $\uparrow$ three IR $\nu_{\mathrm{CO}}$ bands with a weak/ medium/strong intensity pattern were found between 2114 and $2025 \mathrm{~cm}^{-1}$. This is consistent with literature data for other mer,trans $-\left[\mathrm{Os}(\mathrm{H})(\mathrm{CO})_{3}\left(\mathrm{PR}_{3}\right)_{2}\right]^{+} \mathrm{X}^{-}$species $^{24}$ and can be derived theoretically. ${ }^{26}$ The $\nu_{\mathrm{OsH}}$ bands have been identified for related complexes (ca. $\left.2000 \mathrm{~cm}^{-1}, \mathrm{~m}\right),{ }^{24}$ and broad, weaker bands were apparent with our compounds (1964-1967 $\left.\mathrm{cm}^{-1}\right)$. However, no effort was made to unambiguously assign them by preparing deuterated analogs.

\section{Substitution and other reactions}

Replacements of the halide ligands in the osmium(II) complexes were attempted next. As shown in Scheme 4, the gyroscope like dichloride complex $\mathbf{6 a}$ or the phosphacycle containing species $\mathbf{6}^{\prime} \mathbf{b}$ were treated with MeLi in THF. Workups gave the dimethyl complexes cis,cis,trans$\mathrm{Os}(\mathrm{CO})_{2}(\mathrm{Me})_{2}\left(\mathrm{P}\left(\left(\mathrm{CH}_{2}\right)_{14}\right)_{3} \mathrm{P}\right) \quad$ (11a) or cis, cis, trans$\mathrm{Os}(\mathrm{CO})_{2}(\mathrm{Me})_{2}\left(\mathrm{P}\left(\mathrm{CH}_{2}\right)_{15} \mathrm{CH}_{2}\right)\left(\left(\mathrm{CH}_{2}\right)_{16}\right)\left(\mathrm{P}\left(\mathrm{CH}_{2}\right)_{15} \mathrm{CH}_{2}\right) \quad\left(\mathbf{1 1}^{\prime} \mathbf{b}\right) \quad$ in $98 \%$ yields. The structures followed readily from their spectroscopic properties. For example, the ${ }^{1} \mathrm{H}$ and ${ }^{13} \mathrm{C}$ NMR spectra showed characteristic upfield phosphorus coupled triplets for the methyl groups (0.05 or $0.20 \mathrm{ppm}$ and -21.0 or $-25.3 \mathrm{ppm})$. The ${ }^{31} \mathrm{P}$ NMR signals $(-21.0$ or $-25.3 \mathrm{ppm})$ were significantly upfield from those of the precursors. The ${ }^{13} \mathrm{C}$ NMR spectrum of 11a showed seven methylene signals, indicative of rapid $\mathrm{Os}(\mathrm{CO})_{2}(\mathrm{Me})_{2}$ rotation. Other NMR data are collected in Table 1. The IR $\nu_{\mathrm{CO}}$ bands (Table 1 ) were at lower frequencies than those of the precursors $\left(48-59 \mathrm{~cm}^{-1}\right)$, consistent with enhanced backbonding.

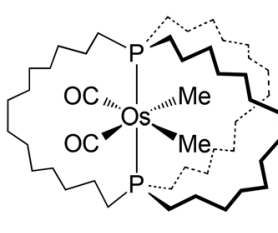

$11 \mathrm{a}, 98 \%$ (from $6 a$ )



6a, $X=\mathrm{Cl}$

7a, $\mathrm{X}=\mathrm{Br}$

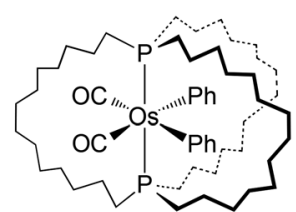

$12 a, 58 \%$ (from $7 a)$

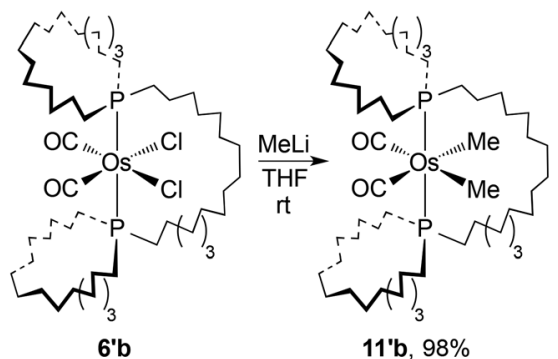

Scheme 4 Substitutions of halide ligands by carbon nucelophiles. 
It was then sought to introduce significantly larger ligands that would preclude rotation of the rotator. In previous studies of gyroscope like complexes, it has proved possible to replace halide ligands by phenyl ligands utilizing $\mathrm{Ph}_{2} \mathrm{Zn}^{8,11}$ Accordingly, 6a, 7a, and $\mathbf{6}^{\prime} \mathbf{b}$ were combined with $\mathrm{Ph}_{2} \mathrm{Zn}$ in refluxing THF. After several days, ${ }^{31} \mathrm{P}$ NMR spectra showed no reaction. Similar results were obtained with $\mathrm{PhMgBr}$. However, as shown in Scheme 4, a reaction of $7 \mathbf{a}$ and $\mathrm{PhLi}$ in refluxing THF gave the desired diphenyl complex cis,cis,trans$\mathrm{Os}(\mathrm{CO})_{2}(\mathrm{Ph})_{2}\left(\mathrm{P}\left(\left(\mathrm{CH}_{2}\right)_{14}\right)_{3} \mathrm{P}\right)(\mathbf{1 2 a})$ in $58 \%$ yield after working. Most spectroscopic data were similar to those of 11a.

Fig. 2 shows a portion of the ${ }^{13} \mathrm{C}$ NMR spectrum of 12a. The three $\left(\mathrm{CH}_{2}\right)_{14}$ chains gave a total of fourteen signals, consisting of two sets of seven with an approximate $2: 1$ intensity ratio. All of the above gyroscope like complexes with $\left(\mathrm{CH}_{2}\right)_{14}$ chains exhibited only seven signals. X-ray crystallography (below) suggests that the unique methylene chain is located between the two cis phenyl ligands, as shown in VI (Fig. 2). However, the spectroscopic data do not exclude the alternative conformation VII. The virtual triplets associated with the $\mathrm{PCH}_{2} \mathrm{CH}_{2} \mathrm{CH}_{2}$ signals of the all the preceding compounds are also apparent in Fig. 2 (three overlap with other signals).

It has been shown that reactions of iron tricarbonyl complexes trans- $\mathrm{Fe}(\mathrm{CO})_{3}\left(\mathrm{PPh}_{3}\right)_{2}$ as well as gyroscope like analogs (IV, Scheme 1) with $\mathrm{NO}^{+} \mathrm{X}^{-}\left(\mathrm{X}=\mathrm{PF}_{6}{ }^{-}, \mathrm{BF}_{4}{ }^{-}\right)$give the cationic nitrosyl complexes trans- $\left[\mathrm{Fe}(\mathrm{CO})_{2}(\mathrm{NO})\left(\mathrm{PR}_{3}\right)_{2}\right]^{+} \mathrm{X}^{-}$in high yields. ${ }^{7,27}$ However, many attempts to carry out analogous substitutions with the osmium(0) tricarbonyl complexes described above failed, as detailed elsewhere. ${ }^{14}$ Close analogs of the target complexes, trans $-\left[\mathrm{Os}(\mathrm{CO})_{2}(\mathrm{NO})\left(\mathrm{PPh}_{3}\right)_{2}\right]^{+} \mathrm{X}^{-}\left(\mathrm{X}^{-}=\right.$ $\left.\mathrm{PF}_{6}{ }^{-}, \mathrm{BPh}_{4}{ }^{-}\right)$have been reported, but were synthesized from the precursor $\mathrm{Os}(\mathrm{H})(\mathrm{Cl})(\mathrm{CO})\left(\mathrm{PPh}_{3}\right)_{3}$, which features three monodentate phosphine ligands. ${ }^{28}$



Fig. 2 Partial ${ }^{13} \mathrm{C}\left\{{ }^{1} \mathrm{H}\right\}$ NMR spectrum $(126 \mathrm{MHz})$ of $12 \mathrm{a}$ illustrating the fourteen $\mathrm{CH}_{2}$ signals consistent with the idealized limiting conformations VI and VII; lines associated with virtual triplets are noted with a *.
The redox properties of selected complexes were probed by cyclic voltammetry using standard conditions. ${ }^{21}$ These included two model osmium(0) species with trialkylphosphine ligands, the trans-Os $(\mathrm{CO})_{3}\left(\mathrm{P}\left(n-\mathrm{C}_{8} \mathrm{H}_{17}\right)_{3}\right)_{2}$ (10a) described above and previously reported trans-Os $(\mathrm{CO})_{3}\left(\mathrm{PCy}_{3}\right)_{2} \cdot{ }^{21}$ Representative traces are shown in Fig. s11. $\uparrow$ The latter complex exhibited a partially reversible oxidation with a current ratio $\left(i_{\mathrm{a}} / i_{\mathrm{c}}\right)$ of 1.08 $\left(E_{\mathrm{p}, \mathrm{a}} / E_{\mathrm{p}, \mathrm{c}} / \Delta E=101 /-139 / 240 \mathrm{mV} ; \mathrm{CH}_{2} \mathrm{Cl}_{2}, 200 \mathrm{mV} \mathrm{s}{ }^{-1}\right)$. In contrast, 10a as well as the osmium(0) complexes 9a,c and $\mathbf{9}^{\prime} \mathbf{b}$ and osmium(II) complex 7a gave irreversible oxidations, with no significant cathodic current on the return scans.

\section{Crystallography: molecular structures}

Although the identities of the complexes in Schemes 2-4 were viewed as secure based upon spectroscopic data, crystal structures of as many as possible were sought. This was motivated by interest in the conformations of the rotators and diphosphine cages (stators), the separations between rotators and neighboring molecules in the solid state, and the alignment of rotators in the solid state - features relevant to developing functional molecular gyroscopes. Crystals of the complexes depicted in Fig. 3-12 were easily obtained as described in the Experimental section, despite the poor reputation associated with molecules with multiple polymethylene segments. ${ }^{29} \mathrm{X}$-ray data were acquired and the structures solved as outlined in



Fig. 3 Thermal ellipsoid plots (50\% probability) of the dominant conformation of 6a: side view (left) and view along the P-Os-P axis (right).



Fig. 4 Thermal ellipsoid plots (50\% probability) of the two independent molecules in the lattice of $6 \mathrm{~b}$ : side views (left) and views along the POs-P axis (right). 

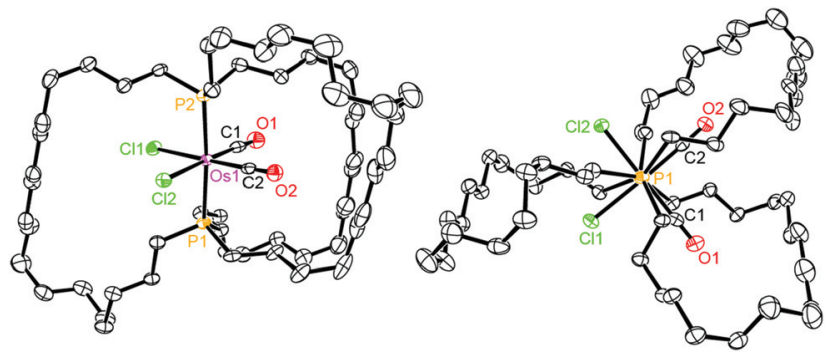

Fig. 5 Thermal ellipsoid plots (50\% probability) of the dominant conformation of $6 \mathrm{c}$ : side view (left) and view along the $\mathrm{P}-\mathrm{Os}-\mathrm{P}$ axis (right).
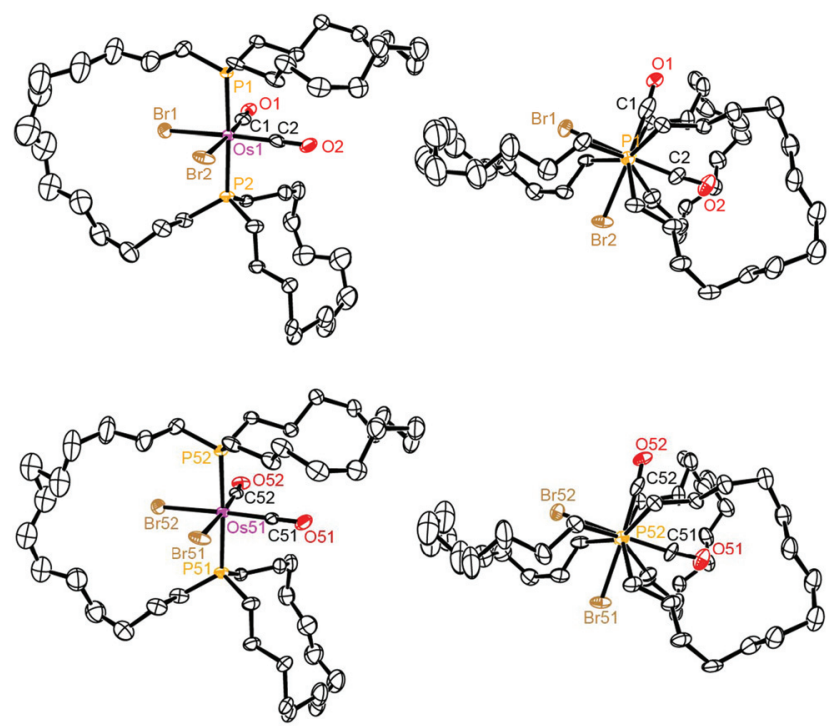

Fig. 6 Thermal ellipsoid plots ( $50 \%$ probability) of the two independent molecules of in the lattice of 7'a: side views (left) and views along the POs-P axis (right).


Fig. 7 Thermal ellipsoid plots (50\% probability) of $7 \mathrm{~b}$ : side view (left) and view along the $\mathrm{P}-\mathrm{Os}-\mathrm{P}$ axis (right).

Table s $2 \uparrow$ and the Experimental section. Key bond lengths and angles have been summarized in Tables 2 and $\mathrm{s} 3 . \dagger$

The gyroscope like dichloride complex $\mathbf{6 a}$, which features seventeen membered macrocycles, showed disorder of one chloride and one CO ligand over two positions. This could be refined to a $51: 49$ occupancy ratio. Two views of the dominant

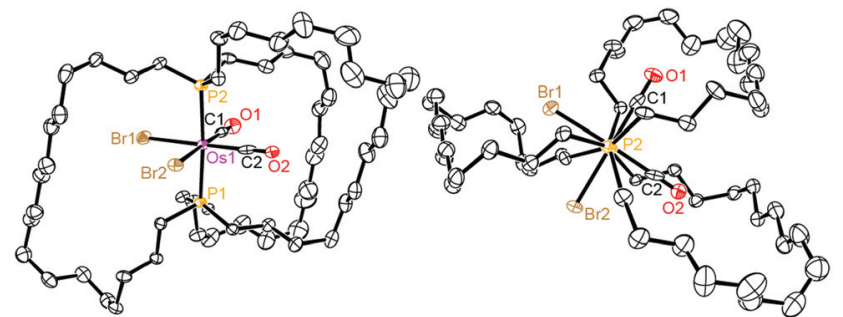

Fig. 8 Thermal ellipsoid plots (50\% probability) of 7c: side view (left) and view along the $\mathrm{P}-\mathrm{Os}-\mathrm{P}$ axis (right).
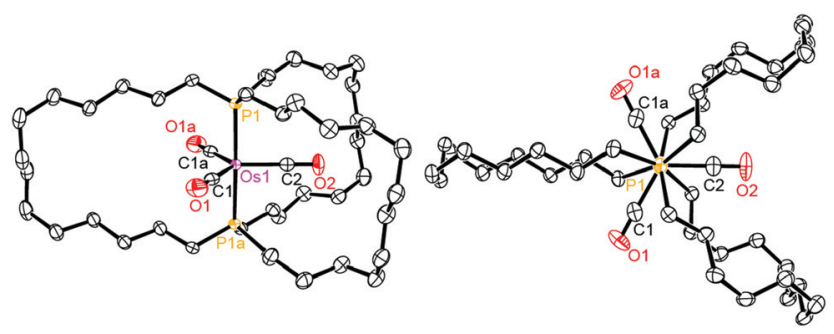

Fig. 9 Thermal ellipsoid plots (50\% probability) of 9a: side view (left) and view along the $\mathrm{P}-\mathrm{O}-\mathrm{P}$ axis (right).
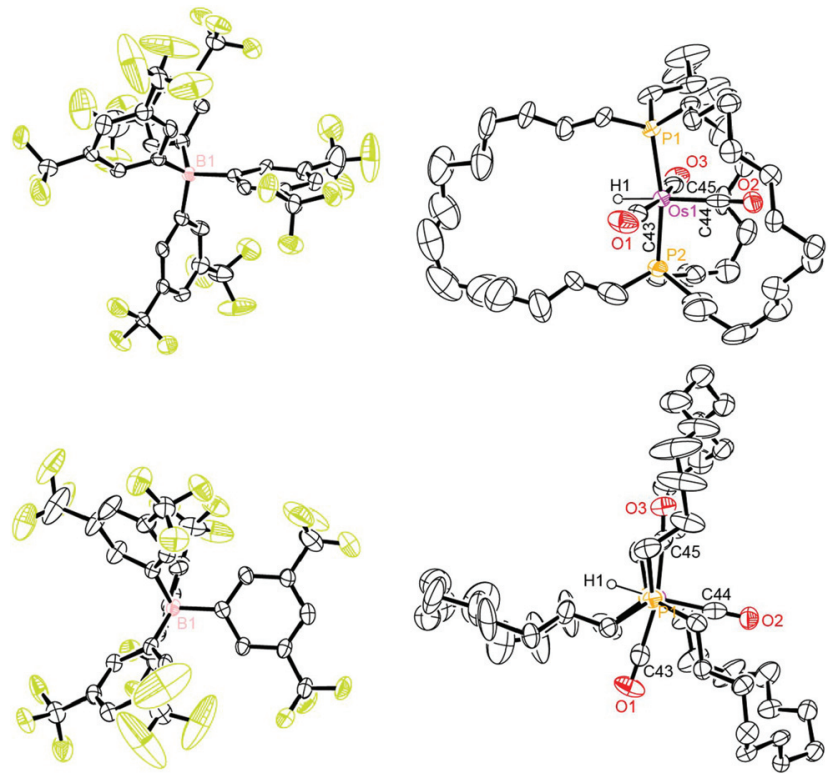

Fig. 10 Thermal ellipsoid plots (50\% probability) of $9 \mathrm{a}-\mathrm{H}^{+} \mathrm{BAr}_{\mathrm{f}}^{-}$: side view (top) and view along the $\mathrm{P}-\mathrm{Os}-\mathrm{P}$ axis (bottom).

conformation are given in Fig. 3, one with the P-Os-P axis in the plane of the paper and the other with the axis perpendicular. Analogous perspectives are provided for the other complexes in subsequent figures.

The unit cell of the dichloride complex $\mathbf{6 b}$, which possesses nineteen membered macrocycles, contained two independent molecules, denoted $\mathbf{6 b}(1)$ and $\mathbf{6 b}(2)$ in the tables. As illustrated in Fig. 4 , these differed in the conformations of the methylene 




Fig. 11 Thermal ellipsoid plots (50\% probability) of 11a: side view (left) and view along the $\mathrm{P}-\mathrm{Os}-\mathrm{P}$ axis (right). Only one rotamer is depicted (occupancy ratio $50: 50$ ).
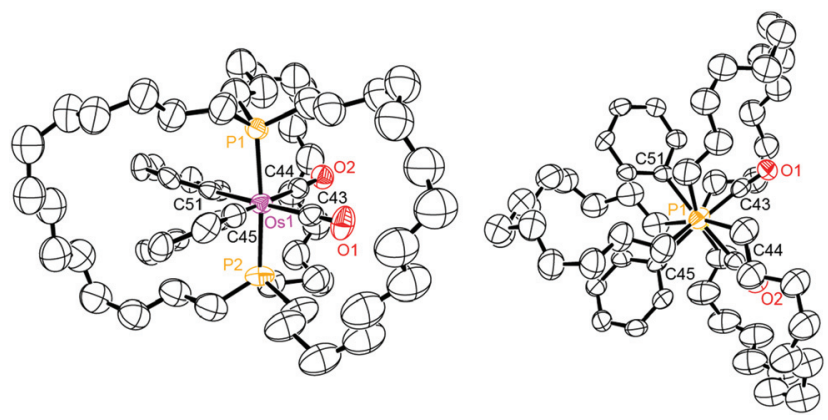

Fig. 12 Thermal ellipsoid plots (50\% probability) of 12a: side view (left) and view along the $\mathrm{P}-\mathrm{O}-\mathrm{P}$ axis (right).

chains. One (bottom, Fig. 4) exhibited whole molecule disorder, which refined to a 53:47 occupancy ratio. The higher homolog 6c, featuring twentyone membered macrocycles, showed disorder of one chloride and one CO ligand over two positions. This refined to an $80: 20$ occupancy ratio, and the dominant conformation is depicted in Fig. 5 .

Fig. 6 illustrates the first crystal structure of a complex derived from mixed intra/interligand metathesis of the precursor I (Scheme 1). Two independent molecules of 7'a were present, distinguished by minor variations in the macrocycle conformations. The crystal structure of the bis $\left(\mathrm{BH}_{3}\right)$ adduct of the free diphosphine ligand has been described elsewhere. ${ }^{30}$ The molecular structures of the gyroscope like dibromide complex $\mathbf{7 b}$ and its longer chain homolog $7 \mathbf{c}$ (nineteen and twentyone membered macrocycles) are given in Fig. 7 and 8 . The latter is quite similar to the dichloride analog $\mathbf{6 c}$ in Fig. 5.

The molecular structure of the gyroscope like osmium(0) complex 9a is depicted in Fig. 9. As with the iron analog (Scheme 1), ${ }^{7}$ a crystallographic $C_{2}$ axis passes through the $\mathrm{M}-\mathrm{C} 2-\mathrm{O} 2$ linkage. It is also worth noting that the osmiumphosphorus distance (2.3626(6) $\AA$ ) is 6\% longer than the ironphosphorus distance $(2.2056(5) \AA)$, providing additional "vertical" clearance for $\mathrm{M}(\mathrm{CO})_{3}$ rotation.

The structure of the corresponding cationic hydride complex $\mathbf{9 a}-\mathrm{H}^{+} \mathrm{BAr}_{\mathrm{f}}^{-}$is given in Fig. 10. The hydride ligand was not located, but the formulation is secure based upon ${ }^{1} \mathrm{H}$ NMR data; the position in Fig. 10 was modeled. Only one cationic hydride complex featuring a $\mathrm{Os}(\mathrm{H})(\mathrm{CO})_{3}$ moiety and trans phosphine ligands could be found in the Cambridge Structural Database. ${ }^{31}$ However, the hydride ligand bridges between osmium and rhodium atoms in that molecule.

The molecular structure of the gyroscope like dimethyl complex 11a is depicted in Fig. 11. One methyl and one CO ligand were disordered over two positions (50:50 occupancy ratio), analogous to the situation with the dichloride complex 6a (Fig. 3). These structures also exhibited very similar macrocycle conformations. The structure of the analogous diphenyl complex 12a is shown in Fig. 12. The phenyl rings are tilted relative to each other, with the least square planes defining an angle of $42^{\circ}$. No other structurally characterized osmium complexes with two cis phenyl ligands could be located. However, crystal structures have been reported for several square planar platinum complexes with cis phenyl or 4-fluorophenyl ligands, and the corresponding angles fall in the range of $50.84-63.60^{\circ} .^{32}$

\section{Crystallography: rotator/stator/lattice analyses}

As noted above, additional features of the preceding crystal structures are of interest. These include the radii of the rotators of the gyroscope like complexes. For the carbonyl halide complexes, the osmium-oxygen (OsCO) distances (2.926-3.126 ̊) are greater than the osmium-halide distances (OsCl 2.346-2.452 ̊; OsBr 2.5805-2.5835 ̊̊). When the van der Waals radius of oxygen is added $(1.52 \AA),{ }^{33}$ an effective rotator radius is obtained; these values (4.503-4.673 $\AA$ ) are compiled in Table 2. Although the van der Waals radii of chlorine and bromine are greater $(1.75 \AA, 1.85 \AA)$, the carbonyl ligands remain "radius determining". The same holds for the tricarbonyl hydride complex $9 \mathrm{a}-\mathrm{H}^{+} \mathrm{BAr}_{\mathrm{f}}^{-}$and the dimethyl complex 11a. With the diphenyl complex 12a, the phenyl ligands are radius determining. When the distance from osmium to the para hydrogen atom is added to the van der Waals radius of a hydrogen atom $(1.20 \AA)$, a value of $7.218 \AA$ is obtained.

Similarly, measures of the void space between the rotator and $\left(\mathrm{CH}_{2}\right)_{n}$ chains of the stator are desirable. For this purpose, the distances from each osmium atom to the two carbon atoms closest to the plane of the rotator can be calculated. These are often the "innermost" $\mathrm{CH}_{2}$ groups, and are abbreviated $\mathrm{C}_{\mathrm{dis}}$ for "distal". However, exceptions exist, as easily visualized from the structures of $\mathbf{6 c}$ and $7 \mathbf{c}$ in Fig. 5 and 8. In any case, the van der Waals radius of an $\mathrm{sp}^{3}$ hybridized carbon atom is then subtracted from these distances. As illustrated in Fig. 13 (left), these six values constitute a type of "horizontal clearance" for the rotator, and are compiled for each complex in Table 2. Although the data can be analyzed in different ways, we usually focus on the shortest distance of the six (see Discussion section). The dihedral angles diagrammed in Fig. 13 (right) are useful in analyzing "vertical clearance" for the rotator (Discussion section).

Intermolecular relationships are also important. For example, the closest contact between each osmium atom and a non-hydrogen atom of a neighboring molecule was identified. For every neutral complex, this involved a methylene carbon 
Table 2 Intramolecular and intermolecular distances involving rotator and stator atoms in gyroscope like complexes [Å], and angles defined by gyroscope axes [ $\left.{ }^{\circ}\right]$

\begin{tabular}{|c|c|c|c|c|c|c|c|c|c|c|}
\hline & $6 a^{a}$ & $\mathbf{6 b}(1)^{b}$ & $\mathbf{6 b}(2)^{b}$ & $6 c^{a}$ & $7 \mathbf{b}$ & $7 c$ & $9 a$ & $9 a-\mathrm{H}^{+} \mathrm{BAr}_{\mathrm{f}}^{-}$ & $11 a^{c}$ & $12 a$ \\
\hline Os-P & $\begin{array}{l}2.4048(5) \\
2.4094(5)\end{array}$ & $\begin{array}{l}2.408(2) \\
2.4087(19)\end{array}$ & $\begin{array}{l}2.404(3) \\
2.406(3)\end{array}$ & $\begin{array}{l}2.3989(7) \\
2.3981(7)\end{array}$ & $\begin{array}{l}2.4137(15) \\
2.4188(15)\end{array}$ & $\begin{array}{l}2.3983(11) \\
2.4041(12)\end{array}$ & $\begin{array}{l}2.3526(5) \\
2.3526(5)\end{array}$ & $\begin{array}{l}2.391(2) \\
2.3928(19)\end{array}$ & $\begin{array}{l}2.3703(11) \\
2.3735(11)\end{array}$ & $\begin{array}{l}2.400(5) \\
2.403(5)\end{array}$ \\
\hline $\mathrm{P}$ to $\mathrm{P}$ & 4.803 & 4.815 & 4.806 & 4.792 & 4.832 & 4.798 & 4.705 & 4.764 & 4.734 & 4.798 \\
\hline $\mathrm{C}-\mathrm{O}$ & $\begin{array}{l}1.134(3) \\
1.159(11)\end{array}$ & $\begin{array}{l}1.016(8) \\
1.135(7)\end{array}$ & $\begin{array}{l}1.038(4) \\
1.104(4)\end{array}$ & $\begin{array}{l}1.122(3) \\
1.132(4)\end{array}$ & $\begin{array}{l}1.105(9) \\
1.116(9)\end{array}$ & $\begin{array}{l}1.053(5) \\
1.119(5)\end{array}$ & $\begin{array}{l}1.159(2) \\
1.159(2) \\
1.165(4)\end{array}$ & $\begin{array}{l}1.112(10) \\
1.125(9) \\
1.152(10)\end{array}$ & $\begin{array}{l}1.150(4) \\
1.219(7) \\
1.220(7)\end{array}$ & $\begin{array}{l}1.136(19) \\
1.156(19)\end{array}$ \\
\hline$\underline{\text { Os-CO }}$ & $\begin{array}{l}1.878(3) \\
1.967(12)\end{array}$ & $\begin{array}{l}1.8827(4) \\
1.9096(4)\end{array}$ & $\begin{array}{l}1.882(4) \\
1.902(4)\end{array}$ & $\begin{array}{l}1.882(3) \\
1.887(3)\end{array}$ & $\begin{array}{l}1.875(8) \\
1.879(8)\end{array}$ & $\begin{array}{l}1.875(4) \\
1.920(5)\end{array}$ & $\begin{array}{l}1.891(3) \\
1.913(2) \\
1.913(2)\end{array}$ & $\begin{array}{l}1.952(10) \\
1.954(9) \\
1.980(10)\end{array}$ & $\begin{array}{l}1.906(3) \\
1.934(7) \\
1.934(7)\end{array}$ & $\begin{array}{l}1.90(2) \\
1.92(2)\end{array}$ \\
\hline$\underline{\mathrm{Os}}-\mathrm{CO}$ & $\begin{array}{l}3.012 \\
3.126\end{array}$ & $\begin{array}{l}2.926 \\
3.018\end{array}$ & $\begin{array}{l}2.928 \\
2.983\end{array}$ & $\begin{array}{l}3.004 \\
3.019\end{array}$ & $\begin{array}{l}2.984 \\
2.991\end{array}$ & $\begin{array}{l}2.973 \\
2.994\end{array}$ & $\begin{array}{l}3.056 \\
3.072 \\
3.072\end{array}$ & $\begin{array}{l}3.076 \\
3.092 \\
3.102\end{array}$ & $\begin{array}{l}3.055 \\
3.151 \\
3.153\end{array}$ & $\begin{array}{l}3.054 \\
3.056\end{array}$ \\
\hline$\frac{\mathrm{Os}^{-}-\mathrm{CO}_{\text {rotor }}{ }^{d}}{\mathrm{Os}-\mathrm{X}^{\underline{e}}}$ & $\begin{array}{l}4.646 \\
2.346(3) \\
2.4469(6)\end{array}$ & $\begin{array}{l}4.538 \\
2.438(2) \\
2.451(2)\end{array}$ & $\begin{array}{l}4.503 \\
2.450(3) \\
2.452(3)\end{array}$ & $\begin{array}{l}4.539 \\
2.4270(9) \\
2.4414(7)\end{array}$ & $\begin{array}{l}4.511 \\
2.5805(7) \\
2.5835(7)\end{array}$ & $\begin{array}{l}4.514 \\
2.5816(9) \\
2.5826(7)\end{array}$ & $\begin{array}{l}4.592 \\
-\end{array}$ & $\begin{array}{l}4.622 \\
1.6002\end{array}$ & $\begin{array}{l}4.673 \\
2.179(7) \\
2.179(7) \\
2.213(3)\end{array}$ & $\begin{array}{l}4.576 \\
5.987 \\
6.018\end{array}$ \\
\hline Os- $\mathrm{X}_{\text {rotor }} e, f$ & 4.197 & 4.201 & 4.202 & 4.1914 & 4.434 & 4.433 & - & 2.8002 & 3.913 & 7.218 \\
\hline Os to $\mathrm{C}_{\mathrm{dis}}{ }^{g}$ & $\begin{array}{l}6.945 / 7.236 \\
6.964 / 7.247 \\
6.610 / 6.612\end{array}$ & $\begin{array}{l}8.025 / 8.080 \\
5.863 / 6.030 \\
6.280 / 6.543\end{array}$ & $\begin{array}{l}6.534 / 7.028 \\
7.204 / 7.526 \\
6.935 / 7.307\end{array}$ & $\begin{array}{l}6.174 / 6.329 \\
5.980 / 6.216 \\
5.861 / 5.910\end{array}$ & $\begin{array}{l}5.938 / 6.861 \\
6.746 / 7.363 \\
6.728 / 7.546\end{array}$ & $\begin{array}{l}5.934 / 6.120 \\
6.454 / 7.205 \\
5.739 / 5.850\end{array}$ & $\begin{array}{l}6.602 / 7.424 \\
7.833 / 7.833 \\
6.602 / 7.424\end{array}$ & $\begin{array}{l}6.865 / 7.494 \\
7.483 / 7.871 \\
6.795 / 7.316\end{array}$ & $\begin{array}{l}6.978 / 7.252 \\
6.627 / 6.662 \\
6.956 / 7.238\end{array}$ & $\begin{array}{l}6.402 / 6.655 \\
6.530 / 7.189 \\
6.620 / 7.453\end{array}$ \\
\hline $\begin{array}{l}\text { Shortest/longest } \\
\text { Os/ } / C_{\text {dis }}-v d W^{h}\end{array}$ & $4.910 / 5.547$ & $4.163 / 6.380$ & $4.834 / 5.826$ & $4.161 / 4.629$ & $4.238 / 5.846$ & $4.039 / 5.505$ & $4.902 / 6.133$ & $5.095 / 6.171$ & $4.841 / 5.552$ & $4.702 / 5.753$ \\
\hline $\begin{array}{l}\text { Os to } C_{\text {inter }}^{i} \\
\text { Os/C } \\
\text { inter-vdW }\end{array}$ & $\begin{array}{l}5.137 \\
3.437\end{array}$ & $\begin{array}{l}5.127 \\
3.427\end{array}$ & $\begin{array}{l}5.745 \\
4.045\end{array}$ & $\begin{array}{l}5.071 \\
3.371\end{array}$ & $\begin{array}{l}4.511 \\
2.811\end{array}$ & $\begin{array}{l}5.401 \\
3.701\end{array}$ & $\begin{array}{l}6.086 \\
4.386\end{array}$ & $\begin{array}{l}4.295^{i} \\
2.795\end{array}$ & $\begin{array}{l}5.161 \\
3.461\end{array}$ & $\begin{array}{l}5.234 \\
3.534\end{array}$ \\
\hline $\begin{array}{l}\text { Sets of parallel } \\
\text { P-Os-P axes }\end{array}$ & 2 & 4 & 1 & 2 & 1 & 1 & 2 & 2 & 2 & 2 \\
\hline$\angle[\mathrm{P}-\mathrm{M}-\mathrm{P}+\mathrm{P}-\mathrm{M}-\mathrm{P}]^{k}$ & 33.25 & $\begin{array}{l}13.85 \\
66.17\end{array}$ & $\begin{array}{l}33.82(2 \times) \\
80.01(2 \times)\end{array}$ & - & 89.98 & - & - & 52.99 & 32.34 & 53.58 \\
\hline$\angle\left[\mathrm{ML}_{n}\right]^{k, l}$ & $31.42(2 \times)$ & $\begin{array}{l}14.95 \\
67.60(2 \times)\end{array}$ & $\begin{array}{l}32.49 \\
80.00(2 \times)\end{array}$ & - & 89.75 & - & - & 58.07 & 30.89 & 56.71 \\
\hline
\end{tabular}

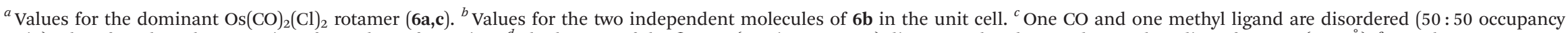

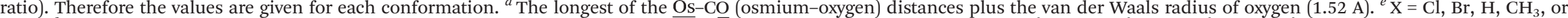

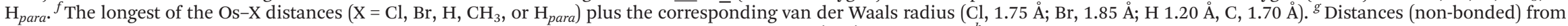

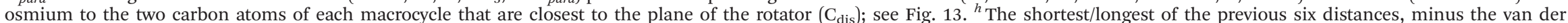

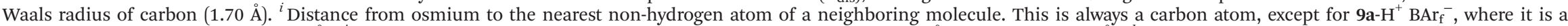


molecules with parallel P-M-P axes; see also the text and Fig. 13. ${ }^{l}$ All ligating atoms of the rotator and osmium; four-five atoms total. 


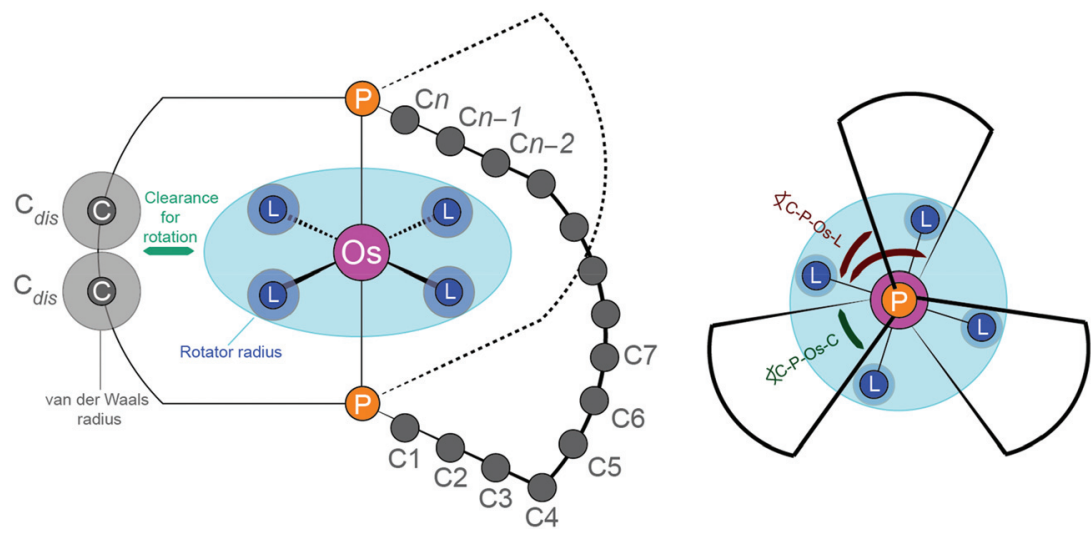

Fig. 13 Spatial relationships involving the osmium rotators and methylene carbon atoms connecting the trans phosphorus atoms.

atom. In the case of $9 \mathrm{a}^{-} \mathrm{H}^{+} \mathrm{BAr}_{\mathrm{f}}^{-}$, a fluorine atom of the anion proved closest. Although there is no requirement that these atoms lie in the plane of the rotator, only moderate deviations would normally be expected. These distances, minus the van der Waals radius of the carbon or fluorine atom, are summarized in Table 2. A value greater than the radius of the rotator would indicate that rotation should not be intramolecularly impeded in the crystal lattice. Only in the case of 9a was this limit approached (4.592 Å radius vs. $4.386 \AA$ intermolecular contact).

In all of the crystal lattices, sets of molecules with parallel P-Os-P axes were apparent. In $\mathbf{6 c}, 7 \mathbf{c}$, and $\mathbf{9 a}$, there was only one such set; i.e., all axes were parallel. This feature is illustrated for 9a in Fig. 14 (left).

A greater number of complexes $-\mathbf{6 a}, \mathbf{7 b}, \mathbf{9 a}-\mathrm{H}^{+} \mathrm{BAr}_{\mathrm{f}}^{-}, \mathbf{1 1 a}$, and 12a - exhibited two distinct sets of molecules with parallel axes. One motif is illustrated with $\mathbf{7 b}$ in Fig. 14 (middle). The angles between these axes were quantified in two ways. First, a plane was defined by taking two axes from one set ( $\mathrm{P}-\mathrm{Os}-\mathrm{P}+\mathrm{P}-\mathrm{Os}-\mathrm{P}$; six atoms total). An analogous plane was defined using the other set. The resulting angles are listed in Table 2. Another calculation was carried out using the rotator planes (all ligating atoms and osmium), and gave similar values. Most of the angles ranged from $57^{\circ}$ to $31^{\circ}$, but 7b was unique in having nearly orthogonal axes (89.8-90.0 $)$.

As noted above, $\mathbf{6 b}$ exhibited two independent molecules in the unit cell. For each, two sets with parallel axes were present, making for multiple angles as listed in Table 2. The unit cell is depicted in Fig. 14 (right), representing the upper limit of complexity, and is not analyzed further.

Finally, it should be emphasized that the osmium tricarbonyl complex 9a crystallizes analogously to the corresponding iron tricarbonyl complex, ${ }^{7}$ with an identical space group $(C 2 / c)$ and $Z$ value (4), and similar unit cell volumes (4693.71(16) vs. 4633.5(3) $\AA^{3}$ ). The slight volume increase reflects the longer metal-ligand bonds per examples given above. All special properties of 9a noted above are also manifested in the iron
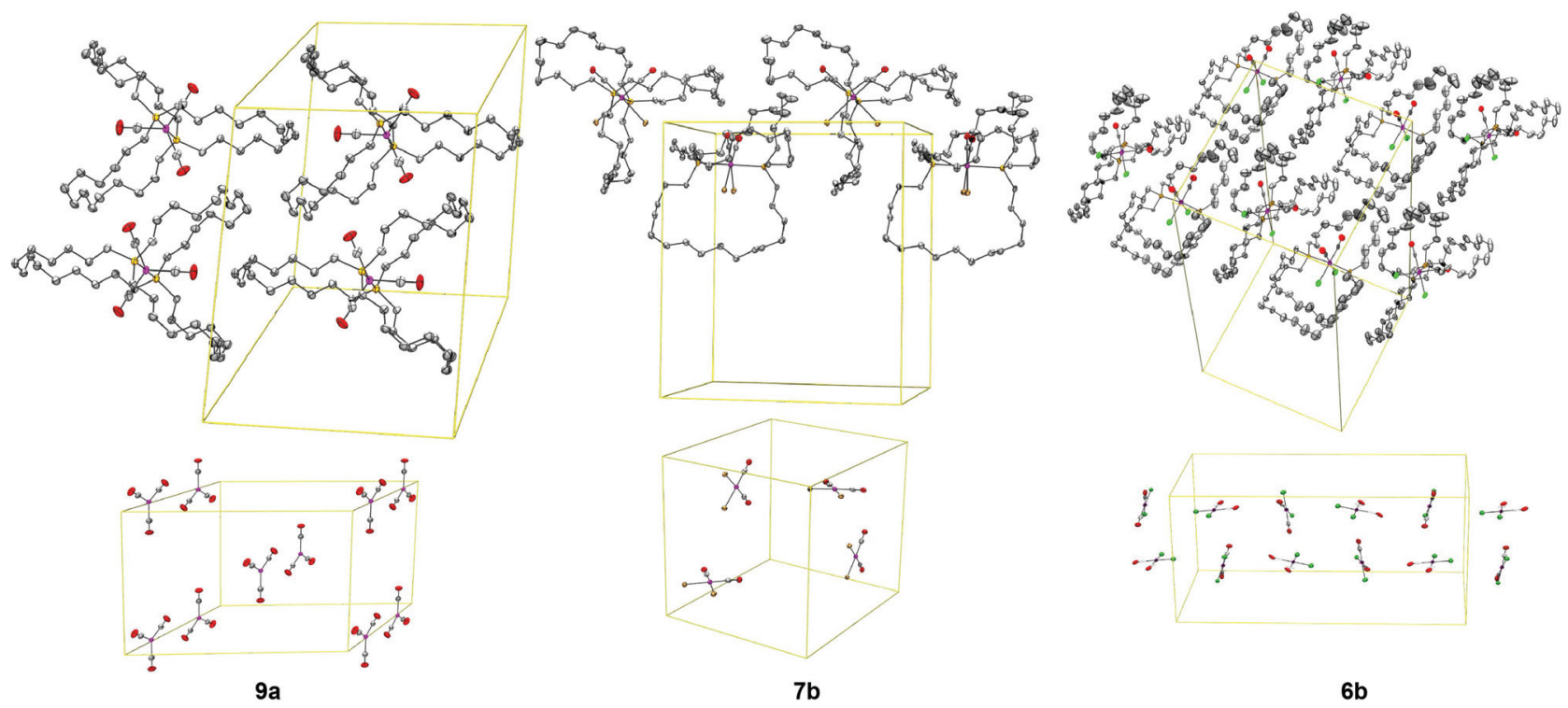

Fig. 14 Packing diagrams of $9 a, 7 b$, and $6 b$ (disordered atoms are depicted in their dominant conformation; the dibridgehead diphosphine ligands are omitted in the bottom representations). 
analog (e.g., radius of rotator $(4.449 \AA)$ only slightly greater than closest intermolecular contact (4.339 ̊)).

\section{Discussion}

\section{Scope of syntheses}

The reaction sequence in Scheme 2 establishes that octahedral $\mathrm{Os}(\mathrm{CO})_{2}(\mathrm{X})_{2}$ based gyroscope like complexes can be accessed via three fold intramolecular ring closing metatheses involving trans phosphine ligands of the formula $\mathrm{P}\left(\left(\mathrm{CH}_{2}\right)_{m} \mathrm{CH}=\mathrm{CH}_{2}\right)_{3}$ with $m \geq 6$. The overall yields of $\mathbf{6 a - c}$ and $7 \mathbf{a}-\mathbf{c}$ are modest (31-5\%), but given the obvious possibilities for oligomeric or polymeric byproducts, it is perhaps surprising that they are obtained at all. As noted above, this study was in part prompted by analogous syntheses of related adducts with Re $(\mathrm{CO})_{3}(\mathrm{X})$ rotators $(\mathrm{X}=\mathrm{Cl}, \mathrm{Br}) .{ }^{11}$ Here, yields with $m=6(n=14)$ were $61 \%$ for the chloride complex and $37 \%$ for the bromide complex. This reproducible trend has been viewed as a ligand size effect, but the yields for the osmium dichloride and osmium dibromide complexes in Scheme 2 are quite close.

Scheme 2 also establishes the viability of a topologically distinct metathesis mode involving both intraligand and interligand ethene elimination and leading to $\mathbf{6}^{\prime} \mathbf{a}-\mathbf{c}$ and $7^{\prime} \mathbf{a}-\mathbf{c}$. When both types of products are considered, the overall yields of monoosmium complexes range from 56\% to 35\%. Regardless, the yields of gyroscope like complexes remain lower than those commonly obtained from square planar and trigonal bipyramidal precursors (Scheme 1). ${ }^{7-10}$ Fig. 15 provides Newman type
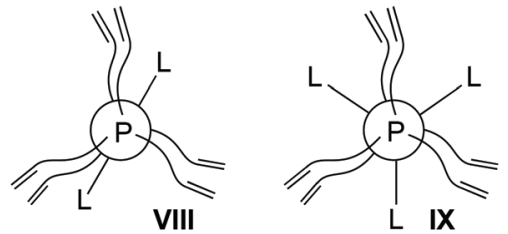

square planar

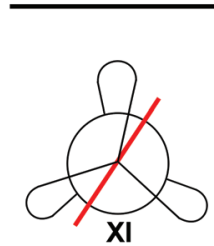

trigonal bipyramidal

ground state
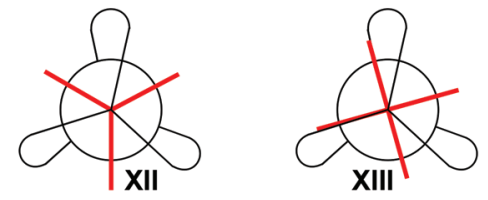

transition state for rotation
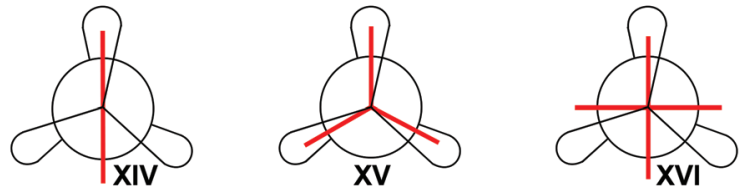

Fig. 15 Top: dominant conformations of square planar, trigonal bipyramidal, and octahedral precursors to gyroscope like complexes. Middle and bottom: energy minima and maxima associated with rotators in square planar, trigonal bipyramidal, and octahedral gyroscope like complexes. projections of the conformational energy minima of each type of educt (VIII-X). It is easily appreciated that the trigonal bipyramidal complexes (IX) are optimally preorganized for three fold interligand metatheses. On the other hand, torsional relationships in the octahedral complexes $(\mathbf{X})$ interfere with the formation of trans spanning linkages. Products analogous to 6'a-c and 7'a-c have never been detected in any metathesis of a trigonal bipyramidal precursor, and are less common with square planar precursors (VIII). ${ }^{8 b, 34}$

Another trend in Scheme 2 involves precursors with even numbers of methylene groups in each phosphine substituent (2a,c, 3a,c) versus those with odd numbers of methylene groups $(\mathbf{2 b}, \mathbf{3 b})$. The former affords ca. $2: 1$ ratios of products derived from interligand $v s$. mixed intra/interligand metathesis modes. However, the latter gives ca. 1:10 ratios. Although the data are suggestive of a broader relationship, a wider range of precursors is needed to confirm generality. Even/odd patterns involving the properties of polymethylene compounds have considerable empirical precedent. ${ }^{35,36}$

We generally view metathesis reactions of I (Scheme 1) to be largely under kinetic control. In an effort to better appreciate the factors that may be at play in Scheme 2, the metathesis of $2 \mathbf{b}$ was repeated, and the crude tris(alkenes) $\left(\mathbf{4}^{*} \mathbf{b}\right.$ or $\left.\mathbf{4 b}^{\mathbf{b}} / \mathbf{4}^{\prime} \mathbf{b}\right)$ divided into two portions. One was hydrogenated, and the other was treated with Grubbs' second generation catalyst, and then hydrogenated. The first sample gave a $1: 6$ ratio of $\mathbf{6 b} / \mathbf{6} \mathbf{b}^{\prime}$, and the latter a ca. 1:16 ratio. Hence, at least for this macrocycle size, the mixed intra/interligand metathesis mode is thermodynamically preferred. In this context, protocols for increasing selectivities for non-oligomeric products in ring closing metathesis have been reported, ${ }^{37}$ and may well prove applicable to our substrates.

Substitution reactions within the diphosphine cages of gyroscope like complexes, such as those presented in Scheme 4 with MeLi and PhLi, now have abundant precedent. $^{8-11}$ Mechanistic questions remain extant, but in a preparative sense the same general reagents may be applied as with analogous bis(phosphine) complexes. The protonation reactions in Scheme 3 also have precedent with bis(phosphine) complexes as well as gyroscope like iron tricarbonyl complexes. What is surprising is the efficacy of a heterogeneous reductant, potassium graphite $\left(\mathrm{C}_{8} \mathrm{~K}\right)$, for converting the osmium(II) dicarbonyl dihalide complexes to osmium(0) tricarbonyl complexes. Apparently, the diphosphine cage does not interfere with a transformation that presumably requires a biphasic outer sphere electron transfer.

\section{Dynamic properties}

When $\mathrm{CD}_{2} \mathrm{Cl}_{2}$ solutions of the trigonal bipyramidal $\mathrm{Fe}(\mathrm{CO})_{2}(\mathrm{NO})^{+}$analog of $\mathbf{9 a}$ are cooled, some of the methylene ${ }^{13} \mathrm{C}$ NMR signals associated with the two inequivalent $\left(\mathrm{CH}_{2}\right)_{14}$ chains decoalesce. This, coupled with line shape analyses, provides a barrier to $\mathrm{Fe}(\mathrm{CO})_{2}(\mathrm{NO})^{+}$rotation $\left(\Delta H^{\ddagger}=\right.$ $\left.9.5 \mathrm{kcal} \mathrm{mol}^{-1} ; \Delta S^{\ddagger}=-6.5 \mathrm{eu}\right) .{ }^{7}$ With the octahedral complexes $6 \mathbf{a}$ and $7 \mathbf{a}$, the barriers to $\mathrm{Os}(\mathrm{CO})_{2}(\mathrm{X})_{2}$ rotation appear lower, as suggested by the absence of any well defined decoalescence 
upon cooling $\left(-100{ }^{\circ} \mathrm{C}\right.$, Fig. s7 $\left.{ }^{\dagger}\right)$. Newman type projections help provide insight regarding this trend.

In the ground state conformations of trigonal bipyramidal complexes (IV, Scheme 1), the ligands on the rotator are approximately staggered with respect to the phosphorus alkyl substituents, as shown in XII in Fig. 15. On the other hand, the transition state for $\mathrm{ML}_{3}$ rotation requires triply eclipsing interactions, with all three ligands simultaneously passing through the three macrocycles (XV). This should maximize the $\Delta G^{\ddagger}$ value. In contrast, the transition state for $\mathrm{ML}_{4}$ rotation in an octahedral complex involves only a single ligand passing through a macrocycle, as shown in XVI (although two other ligands are on the threshold of interacting with the two other macrocycles). Furthermore, in the ground state conformations of octahedral complexes (XIII), there are significant interactions between two ligands and two macrocycles. This translates into a "ground state destabilization" that has no counterpart in the trigonal bipyramidal complexes. The net result is intrinsically lower rotational barriers. ${ }^{38}$

Another way of viewing this phenomenon is that there are twelve energy maxima (and twelve minima) as a rotator in an octahedral complex is stepped through $360^{\circ}$, but only three in the case of a trigonal bipyramidal complex. As has been long appreciated in conformational analyses of organic molecules, it would be very unusual for the maxima/minima for a "twelve fold barrier" to exhibit a greater amplitude than for a "three fold barrier" (with substituents of comparable sizes). ${ }^{38}$ To complete the picture, square planar complexes have a "six fold barrier" as reflected by the minima and maxima XI and XIV. Accordingly, experiments have established that $\mathrm{Rh}(\mathrm{CO})(\mathrm{I})$ has a much lower barrier to rotation than $\mathrm{Rh}(\mathrm{CO})_{2}(\mathrm{I}) .{ }^{10 a}$

Our NMR data also indicate very rapid rotation of the osmium rotators in the dimethyl complex 11a and the cationic hydride complexes $\mathbf{9 a}-\mathrm{H}^{+} \mathrm{X}^{-}$. However, for the diphenyl complex 12a, rotation becomes slow on the NMR time scale, and as illustrated in Fig. 2 two sets of ${ }^{13} \mathrm{C}$ signals for the two macrocycles are observed. However, for none of the complexes in this paper were both the fast and slow exchange regimes accessible, and therefore the exact barriers remain unquantified. It was also a disappointment that trigonal bipyramidal complexes with $\mathrm{Os}(\mathrm{CO})_{2}(\mathrm{NO})^{+}$rotators could not be accessed, since given the results with the iron analog, there would have been a good chance of observing both regimes.

\section{Crystal structures}

As analyzed in more detail elsewhere, ${ }^{14}$ there is nothing exceptional about the bond lengths and angles in the structurally characterized complexes. ${ }^{39}$ Thus, the features most relevant to the dynamic properties treated in the previous section are considered. First, the conformation of the $\mathrm{Os}(\mathrm{CO})_{3}$ rotator in the trigonal bipyramidal complex 9a (Fig. 9, right) closely corresponds to the anticipated energy minimum XII in Fig. 15. Second, the conformations of the $\mathrm{Os}(\mathrm{CO})_{2}(\mathrm{X})_{2}$ rotators in the octahedral complexes 6b,c and 12a (Fig. 4, 5, and 12; right or upper right) closely correspond to the anticipated energy minimum XIII (Fig. 15). However, the rotator conformations in the other octahedral complexes more closely resemble the anticipated energy maximum XVI, with one ligand positioned within a macrocycle (Fig. 3, 7, 8, 10, 11; right). This is interpreted as evidence for the much closer maxima/minima energy spacing in the octahedral complexes.

As noted above, the $\mathrm{Os}(\mathrm{CO})_{\mathrm{z}}(\mathrm{L})_{\mathrm{y}}$ moieties in the octahedral complexes 6a, 7a, 11a, and $9 \mathbf{a}-\mathrm{H}^{+} \mathrm{BAr}_{\mathrm{f}}{ }^{-}$, all of which feature seventeen membered macrocycles, undergo rapid rotation on the NMR time scale at room temperature. Per the results section, computing the radii of the rotators is straight forward. As summarized in Table 2, the carbonyl ligands are "radius determining" in every case (4.622-4.673 $\AA$ for the three of these four complexes that have been structurally characterized). Estimating an "interior void space" or "horizontal clearance" for the stator is less exact. As diagrammed in Fig. 13, we focus upon the two carbon atoms of each macrocycle that are closest to the plane of the rotator $\left(\mathrm{C}_{\mathrm{dis}}\right)$, and subtract the van der Waals radius of a carbon atom from the shortest of the six osmium- $\mathrm{C}_{\mathrm{dis}}$ distances (4.841-5.095 for the three complexes). These are all comfortably longer than the radii of the rotators, a feature nicely illustrated by the space filling representations of $6 \mathbf{a}$ and 9a in Fig. 16. However, other analyses can be considered. For example, given that the macrocycles will exhibit facile conformational equilibria in solution, an average osmium $-\mathrm{C}_{\mathrm{dis}}$ value might be applied. Nonetheless, for the purpose of designing target molecules, we favor the most conservative (space restrictive) approach.

The radius of the phenyl substituted $\mathrm{Os}(\mathrm{CO})_{2}(\mathrm{Ph})_{2}$ rotator in 12a (7.318 ̊) greatly exceeds the horizontal clearances in the complexes with seventeen membered macrocycles

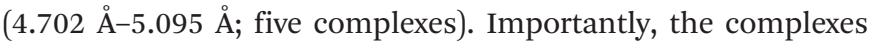
in Table 2 that contain nineteen and twentyone membered macrocycles do not exhibit additional clearance (6b(1), $4.163 \AA$ A;

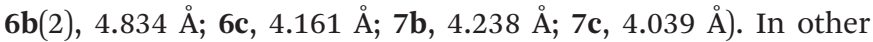
words, larger macrocycles do not necessarily translate into more laterally spacious interior domains, at least in the "snapshots" afforded by crystal structures. For $\mathbf{6 c}$ and $7 \mathbf{c}$, it is easy to see (Fig. 5 and 7) that the "extra length" is applied more in a vertical than horizontal dimension. However, other methylene carbon atoms in $\mathbf{6 c}$ and $7 \mathbf{c}$ extend to nearly the same radius as the phenyl substituted rotator (7.159-7.193 Å). Accordingly, the $\mathrm{Pt}(\mathrm{Ph})_{2}$ rotators in analogous square planar complexes



Fig. 16 Space filling representations of the crystal structures of $6 a$ and 9a illustrating the "horizontal clearance" between the rotator and the distal carbon atoms of the macrocycles. 
undergo rapid rotation through twentyone membered macrocycles, but are blocked by seventeen membered macrocycles. ${ }^{8 b}$

In an earlier study involving large numbers of crystal structures of square planar gyroscope like platinum and palladium complexes, the gauche/anti torsional sequences in the macrocycles were mapped, but little was found in the way of "conserved motifs" or common features. ${ }^{8 b}$ The situation is similar for the structurally characterized osmium complexes in Fig. 3-12, and therefore these data are archived in the ESI (Table s3†). However, with a single exception, all of the $\mathrm{P}-$ $\mathrm{CH}_{2}-\mathrm{CH}_{2}-\mathrm{CH}_{2}$ segments exhibit anti conformations, with torsion angles ranging from $\pm 153.53^{\circ}$ to $\pm 179.50^{\circ}$.

In connection with the $\mathrm{P}-\mathrm{CH}_{2}-\mathrm{CH}_{2}-\mathrm{CH}_{2}$ segments, another consideration briefly mentioned above concerns the vertical or "top/bottom" clearance associated with the stators. In other words, to what extent does a rotator substituent passing through the macrocycle interact with the phosphorus bound methylene groups $\mathrm{H}_{2} \underline{\mathrm{C}}-\mathrm{P}-\mathrm{M}-\mathrm{P}-\mathrm{CH}_{2}$ ? This is best appreciated by referring to the representations in Fig. 17, which show typical dichloride (6a) and dibromide (7b) complexes with key atoms at van der Waals radii. Moderate interactions are evident, some of which will increase as the rotators rotate. Those within the dibromide complex are greater.

In terms of metrics, the $\mathrm{H}_{2} \underline{\mathrm{C}}-\mathrm{P}-\mathrm{P}-\mathrm{CH}_{2}$ torsion angles within each macrocycle (Fig. 13, right) average $25.17^{\circ}$ for the octahedral complexes (for trigonal bipyramidal 9a, 38.13). The corresponding carbon-carbon distances range from $5.947 \AA$ to $6.656 \AA$. When the van der Waals radii of two carbon atoms are subtracted $(3.40 \AA)$, effective clearances of $2.547 \AA$ to $3.256 \AA$ are obtained. In all cases, these values are smaller than the ligand with the largest diameter (van der Waals diameter of $\mathrm{Br}, 3.70 \AA$; $\mathrm{Cl}, 3.50 \AA$; $\mathrm{C}, 3.40 \AA$; said differently, in this dimension that "fatness" of the rotator trumps the radius). Thus, the attendant steric interactions must con-

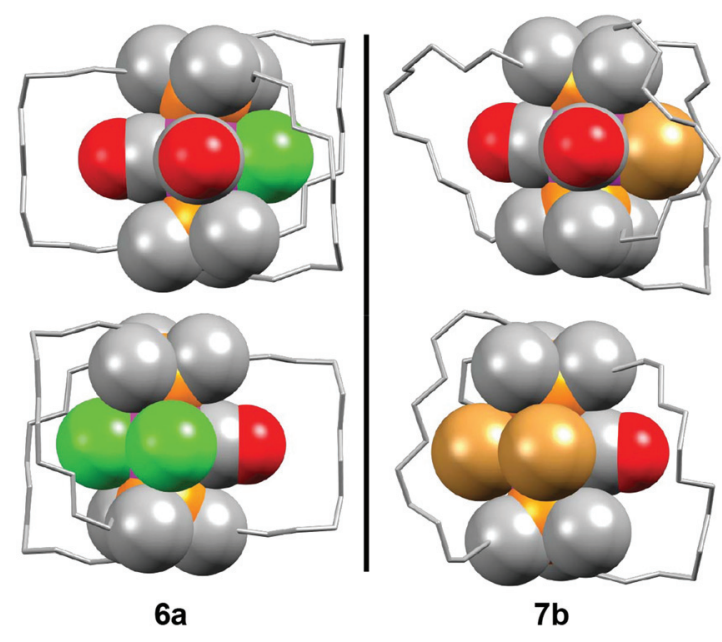

Fig. 17 Crystal structures of the octahedral dichloride and dibromide complexes $6 \mathbf{a}$ and $7 \mathrm{~b}$ illustrating the "vertical clearance" between ligands on the rotators (chloride or bromide, $\mathrm{CO}$ ) and the $\mathrm{P}\left(\mathrm{CH}_{2}\right)_{3}$ moieties of the stators (these atoms shown at van der Waals radii). tribute to the rotational barriers. This furthermore suggests, in accord with intuitive expectations, that the rotation of the rotator is correlated to conformational changes in the macrocycles that expand these distances.

Anything that can increase the dimensions imposed by the stator should attenuate the "friction" associated with rotation of the rotator, and the lower barriers should give more effective molecular gyroscopes. Obviously, interactions are reduced upon going from iron to osmium based stators and rotators, and as is currently under study with iron analogs, from phosphorus to arsenic or antimony containing stators. ${ }^{40}$ Another strategy would involve replacing the ligating phosphorus atoms with alkynyl groups.

As briefly noted in the results section and reflected by the data in Table 2, there is only one adduct in which the osmium rotator may be able to rotate in the solid state without being significantly impeded by a neighboring molecule, namely trigonal bipyramidal 9a (4.592 Å rotator radius vs. $4.386 \AA$ closest contact). Interestingly, this is found quite often in the crystal structures of neutral trigonal bipyramidal gyroscope like complexes. ${ }^{41}$ Therefore, with this class of compounds it may be possible to realize molecular gyroscopes both in solution and the solid state. The latter would represent, in the GarciaGaribay formalism, "amphidynamic crystals". 4

\section{Summary and prospective}

Scheme 1 has been successfully extended to syntheses of gyroscope like complexes with $\mathrm{Os}(\mathrm{CO})_{2}(\mathrm{X})_{2}$ rotators $(\mathrm{X}=\mathrm{Cl}, \mathrm{Br})$ and stators comprised of trans spanning $\mathrm{P}\left(\mathrm{CH}_{2}\right)_{n} \mathrm{P}$ linkages $(n=14$, $16,18)$. However, they are accompanied by isomers derived from a mixed intra/interligand metathesis mode, which dominate in the case of $n=16$. The chloride or bromide ligands in these octahedral systems undergo both substitution and reduction, with the latter affording (under CO atmospheres) trigonal bipyramidal gyroscope like complexes with $\mathrm{Os}(\mathrm{CO})_{3}$ rotators. These can be protonated by acids HX to give octahedral cationic hydride complexes.

The rotators of all of these complexes except a $\mathrm{Os}(\mathrm{CO})_{2}(\mathrm{Ph})_{2}$ species undergo rapid rotation on the NMR time scale in solution at room temperature or below. For the octahedral complexes, this ease has been attributed to a combination of ground state strain and fewer eclipsing interactions in the transition state. Many of the gyroscope like complexes can be crystallized, but except for the $\mathrm{Os}(\mathrm{CO})_{3}$ species $(n=14)$, rotations of the rotators are blocked by intermolecular contacts in the solid state.

These data are part of a larger body of work directed at enhancing the void space within the cage like stators, such that rotational barriers are minimized. In all of these molecules, rotation is Brownian - i.e., both clockwise and counterclockwise. However, unidirectional rotation is required for gyroscopic properties. Towards this end, any dipole moment associated with a rotator can be used to orient the rotator in a static electric field, or drive rotation in a rotating electric field. $^{2,42}$ All of the compounds described above except 9a feature dipolar rotators, but for various reasons most are less 
than ideal (e.g., with salts, interactions with counter ions lead to increased barriers). However, many attractive derivatives or homologs are easily identified, and these will be synthesized and investigated in future reports from this laboratory.

\section{Experimental section}

The full Experimental section is provided in the ESI. $\uparrow$ The portion presented below is restricted to one representative procedure for each type of transformation. Homologous or isomeric compounds were synthesized analogously. Full spectroscopic data are presented in the ESI. $\dagger$

\section{cis, cis, trans- $\mathrm{Os}(\mathrm{CO})_{2}(\mathrm{Cl})_{2}\left(\mathrm{P}\left(\left(\mathrm{CH}_{2}\right)_{6} \mathrm{CH}=\mathrm{CH}_{2}\right)_{3}\right)_{2}(2 \mathrm{a})$}

A Fischer-Porter bottle was charged with $\left(\mathrm{NH}_{4}\right)_{2} \mathrm{OsCl}_{6}(0.507 \mathrm{~g}$, $1.16 \mathrm{mmol}$ ) and 2-methoxyethanol $(40 \mathrm{~mL})$. The red suspension was stirred at $110{ }^{\circ} \mathrm{C}$ under CO (10 bar) until it turned pale yellow (5-7 d). Then $1 \mathrm{a}(1.55 \mathrm{~g}, 4.25 \mathrm{mmol})$ was added with stirring and the solution kept at $80{ }^{\circ} \mathrm{C}$ for $24 \mathrm{~h}$. The solvent was removed by oil pump vacuum and the resulting red-brown oil chromatographed $\left(\mathrm{SiO}_{2}\right.$ column, $3.5 \mathrm{~cm} \times 30 \mathrm{~cm}$, $2: 1 \mathrm{v} / \mathrm{v}$ hexanes $/ \mathrm{CH}_{2} \mathrm{Cl}_{2}$ ). The solvent was removed from the product containing fractions by oil pump vacuum to give $2 \mathbf{a}$ $(0.883 \mathrm{~g}, 0.844 \mathrm{mmol}, 73 \%)$ as a pale yellow oil. Anal. calcd (\%) for $\mathrm{C}_{50} \mathrm{H}_{90} \mathrm{Cl}_{2} \mathrm{O}_{2} \mathrm{P}_{2} \mathrm{Os}$ (1046.33): C 57.39, $\mathrm{H}$ 8.67; found $\mathrm{C} 56.97$, H 8.74.

cis, cis, trans $-\mathrm{Os}(\mathrm{CO})_{2}(\mathrm{Br})_{2}\left(\mathrm{P}\left(\left(\mathrm{CH}_{2}\right)_{6} \mathrm{CH}=\mathrm{CH}_{2}\right)_{3}\right)_{2}(3 \mathrm{a})$

A Fischer-Porter bottle was charged with $\left(\mathrm{NH}_{4}\right)_{2} \mathrm{OsBr}_{6}(0.500 \mathrm{~g}$, $0.709 \mathrm{mmol}$ ) and 2-methoxyethanol $(40 \mathrm{~mL})$. The deep red solution was stirred at $80{ }^{\circ} \mathrm{C}$ under $\mathrm{CO}(10 \mathrm{bar})$ until it turned pale yellow (3-5 d). Then 1a (0.950 g, $2.61 \mathrm{mmol})$ was added with stirring and the solution kept at $80{ }^{\circ} \mathrm{C}$ for $24 \mathrm{~h}$. The solvent was removed by oil pump vacuum and the resulting red-brown oil chromatographed $\left(\mathrm{SiO}_{2}\right.$ column, $3.5 \mathrm{~cm} \times 30 \mathrm{~cm}$, $5: 2 \mathrm{v} / \mathrm{v}$ hexanes $/ \mathrm{CH}_{2} \mathrm{Cl}_{2}$ ). The solvent was removed from the product containing fractions by oil pump vacuum to give $3 \mathbf{a}$ $(0.441 \mathrm{~g}, 0.388 \mathrm{mmol}, 55 \%)$ as a pale yellow oil. Anal. calcd (\%) for $\mathrm{C}_{50} \mathrm{H}_{90} \mathrm{Br}_{2} \mathrm{O}_{2} \mathrm{P}_{2} \mathrm{Os}$ (1135.23): C 52.90, $\mathrm{H}$ 7.99; found $\mathrm{C} 53.22$, H 8.26.

\section{Alkene metathesis of $2 a$}

A Schlenk flask was charged with $2 \mathrm{a}(0.714 \mathrm{~g}, 0.683 \mathrm{mmol})$ and chlorobenzene $(700 \mathrm{~mL}$; the resulting solution was $0.0010 \mathrm{M}$ ). Then solid Grubbs' catalyst (0.039 g, $0.048 \mathrm{mmol}, 7.0 \mathrm{~mol} \%$ ) was added with stirring. The solution was aspirated with $\mathrm{N}_{2}$, and periodically monitored by ${ }^{1} \mathrm{H}$ NMR. After the reaction was complete (ca. $24 \mathrm{~h}$ ), the solution was aspirated with air (30 $\mathrm{min}$ ) to decompose the remaining catalyst. The solution was filtered through $\mathrm{Al}_{2} \mathrm{O}_{3}(3 \mathrm{~cm} \times 5 \mathrm{~cm})$, which was washed with $\mathrm{CH}_{2} \mathrm{Cl}_{2}$. The solvents were removed from the filtrate to give crude $4^{*} \mathrm{a}(0.571 \mathrm{~g}, 0.594 \mathrm{mmol}, 87 \%)$ as a light brown sticky oil. cis, cis, trans- $\mathrm{Os}(\mathrm{CO})_{2}(\mathrm{Cl})_{2}\left(\mathrm{P}\left(\left(\mathrm{CH}_{2}\right)_{14}\right)_{3} \mathrm{P}\right)(6 \mathrm{a})$ and cis, cis, trans$\mathrm{Os}(\mathrm{CO})_{2}(\mathrm{Cl})_{2}\left(\mathbf{P}\left(\mathrm{CH}_{2}\right)_{13} \mathrm{CH}_{2}\right)\left(\left(\mathrm{CH}_{2}\right)_{14}\right)\left(\mathbf{P}\left(\mathrm{CH}_{2}\right)_{13} \mathrm{CH}_{2}\right)$ (6'a)

A Schlenk flask was charged with $4^{*}$ a $(0.571 \mathrm{~g}, 0.594 \mathrm{mmol}$; the entire quantity prepared above), THF (30 mL), and $\mathrm{PtO}_{2}$ (0.023 g, $0.102 \mathrm{mmol})$, connected to a gas balloon, and partially evacuated. Then $\mathrm{H}_{2}$ ( 1 bar) was introduced, and the suspension was stirred. After $3 \mathrm{~d}$, the solvent was removed by oil pump vacuum. The black residue was filtered through $\mathrm{Al}_{2} \mathrm{O}_{3}$ with $\mathrm{CH}_{2} \mathrm{Cl}_{2}$. The solvent was removed from the filtrate and the residue was chromatographed $\left(\mathrm{SiO}_{2}\right.$ column, $3.5 \mathrm{~cm} \times$ $30 \mathrm{~cm}, 3: 2 \mathrm{v} / \mathrm{v}$ hexanes $\left./ \mathrm{CH}_{2} \mathrm{Cl}_{2}\right)$. The solvents were removed from the product containing fractions by oil pump vacuum to give $6 \mathrm{a}(0.186 \mathrm{~g}, 0.192 \mathrm{mmol}, 28 \%$ from $2 \mathrm{a})$ as a white solid and 6'a (0.084 g, $0.087 \mathrm{mmol}, 13 \%$ from 2a) as a colorless sticky oil that solidified after one week.

6a: Dec. pt. (capillary) $260{ }^{\circ} \mathrm{C} .{ }^{43}$ DSC $\left(T_{\mathrm{i}} / T_{\mathrm{e}} / T_{\mathrm{p}} / T_{\mathrm{c}} / T_{\mathrm{f}}\right):{ }^{44}$ 32.3/39.6/41.1/42.7/56.1 ${ }^{\circ} \mathrm{C}$ (endotherm); 74.0/84.5/85.8/87.6/ $109.2^{\circ} \mathrm{C}$ (endotherm); 165.6/181.5/183.1/184.8/199.0 ${ }^{\circ} \mathrm{C}$ (endotherm), 244.5/248.0/253.4/258.2/273.3 ${ }^{\circ} \mathrm{C}$ (endotherm). TGA: onset of mass loss, $295.0{ }^{\circ} \mathrm{C}$. Anal. calcd (\%) for $\mathrm{C}_{44} \mathrm{H}_{84} \mathrm{Cl}_{2} \mathrm{O}_{2} \mathrm{P}_{2} \mathrm{Os}$ (968.22): C 54.58, $\mathrm{H}$ 8.74; found $\mathrm{C}$ 55.01, H 8.90 .

6'a: $\mathrm{mp}$ (capillary) $67{ }^{\circ} \mathrm{C}$. Anal. calcd (\%) for $\mathrm{C}_{44} \mathrm{H}_{84} \mathrm{Cl}_{2}$ $\mathrm{O}_{2} \mathrm{P}_{2} \mathrm{Os}$ (968.22): C 54.58, H 8.74; found C 54.58, H 8.70.

\section{trans- $-\widehat{\mathrm{Os}(\mathrm{CO})_{3}\left(\mathrm{P}\left(\left(\mathrm{CH}_{2}\right)_{14}\right)_{3} \mathrm{P}\right)}(\mathbf{9 a})$}

A Schlenk flask was charged with $2 \mathrm{a}(0.100 \mathrm{~g}, 0.107 \mathrm{mmol})$ or 3a $(0.100 \mathrm{~g}, 0.098 \mathrm{mmol})$ and THF $(10 \mathrm{~mL})$. The solution was aspirated with $\mathrm{CO}$ (15 min). Then a suspension of $\mathrm{C}_{8} \mathrm{~K}$ (0.331 g, $2.45 \mathrm{mmol}$ or $0.361 \mathrm{~g}, 2.68 \mathrm{mmol})$ in THF $(10 \mathrm{~mL})$ was slowly added. The reaction was monitored by ${ }^{31} \mathrm{P}$ NMR. After the educt had been consumed, graphite powder and unreacted $\mathrm{C}_{8} \mathrm{~K}$ were removed by cannula filtration. The filtrate was concentrated to $5 \mathrm{~mL}$ by oil pump vacuum, and $\mathrm{MeOH}$ $(20 \mathrm{~mL})$ was added. The colorless precipitate was isolated by filtration and washed with $\mathrm{MeOH}$. The filter was rinsed with $\mathrm{CH}_{2} \mathrm{Cl}_{2}$ to dissolve the product and remove insoluble solids. The solvent was removed from the filtrate and the residue dried by oil pump vacuum to give 9a $(0.086 \mathrm{~g}, 0.093 \mathrm{mmol}$, $87 \%$, or $0.074 \mathrm{~g}, 0.080 \mathrm{mmol}, 82 \%$ ) as a white solid, $\mathrm{mp}$ $248{ }^{\circ} \mathrm{C}$, dec (gradual darkening, $>180{ }^{\circ} \mathrm{C}$; capillary). DSC $\left(T_{\mathrm{i}} / T_{\mathrm{e}} /\right.$ $\left.T_{\mathrm{p}} / T_{\mathrm{c}} / T_{\mathrm{f}}\right)::^{44} 94.7 / 95.3 / 118.1 / 127.8 / 127.8^{\circ} \mathrm{C}$ (endotherm, minor); 127.9/144.9/148.3/150.5/155.8 ${ }^{\circ} \mathrm{C}$ (endotherm). TGA: onset of mass loss, $230.6{ }^{\circ} \mathrm{C}$. Anal. calcd (\%) for $\mathrm{C}_{45} \mathrm{H}_{84} \mathrm{O}_{3} \mathrm{P}_{2} \mathrm{Os}$ (925.32): C 58.41, H 9.15; found C 58.38, H 8.80.

\section{mer,trans $-\left[\longdiv { \mathrm { Os } ( \mathrm { H } ) ( \mathrm { CO } ) _ { 3 } ( \mathrm { P } ( ( \mathrm { CH } _ { 2 } ) _ { 1 4 } ) _ { 3 } \mathrm { P } ) }\right]^{+} \mathrm{CF}_{3} \mathrm{SO}_{3}{ }^{-}\left(9 \mathrm{a}-\mathrm{H}^{+} \mathrm{CF}_{3} \mathrm{SO}_{3}{ }^{-}\right)$}

A $5 \mathrm{~mm}$ NMR tube was charged with 9a $(0.010 \mathrm{~g}, 0.011 \mathrm{mmol})$, $\mathrm{CDCl}_{3}(0.5 \mathrm{~mL})$, and $\mathrm{CF}_{3} \mathrm{SO}_{3} \mathrm{H}(0.002 \mathrm{~mL}, 0.02 \mathrm{mmol})$. NMR spectra showed the quantitative generation of $9 \mathrm{a}-\mathrm{H}^{+} \mathrm{CF}_{3} \mathrm{SO}_{3}{ }^{-}$.

\section{mer,trans $-\left[\longdiv { \mathrm { Os } ( \mathrm { H } ) ( \mathrm { CO } ) _ { 3 } ( \mathrm { P } ( ( \mathrm { CH } _ { 2 } ) _ { 1 4 } ) _ { 3 } \mathrm { P } ) }\right]^{+} \mathrm{BAr}_{\mathrm{f}}^{-}\left(9 \mathrm{a}-\mathrm{H}^{+} \mathrm{BAr}_{\mathrm{f}}{ }^{-}\right)$}

A Schlenk flask was charged with 9a $(0.047 \mathrm{~g}, 0.051 \mathrm{mmol})$, $\mathrm{CH}_{2} \mathrm{Cl}_{2}(10 \mathrm{~mL})$, and $\left[\mathrm{H}\left(\mathrm{OEt}_{2}\right)_{2}\right]^{+} \mathrm{BAr}_{\mathrm{f}}^{-}(0.052 \mathrm{~g}, 0.051 \mathrm{mmol})$ 
with stirring. After $24 \mathrm{~h}$, the solvent was removed by oil pump vacuum. The residue was washed with hexanes and dried by oil pump vacuum to give $9 \mathrm{a}-\mathrm{H}^{+} \mathrm{BAr}_{\mathrm{f}}^{-}(0.073 \mathrm{~g}, 0.041 \mathrm{mmol}$, $80 \%$ ) as a colorless powder, mp $181{ }^{\circ} \mathrm{C}$ (capillary). TGA: ${ }^{44}$ onset of mass loss, $190.9{ }^{\circ} \mathrm{C}$. Anal. calcd (\%) for $\mathrm{C}_{77} \mathrm{H}_{97^{-}}$ $\mathrm{BF}_{24} \mathrm{O}_{3} \mathrm{P}_{2} \mathrm{Os}$ (1789.54): C 51.68, H 5.46; found C 51.96, H 5.63.

\section{cis, cis,trans- $\overline{\mathrm{Os}(\mathrm{CO})_{2}(\mathrm{Me})_{2}\left(\mathrm{P}\left(\left(\mathrm{CH}_{2}\right)_{14}\right)_{3} \mathrm{P}\right)}(11 \mathrm{a})$}

A Schlenk flask was charged with $6 \mathbf{6}(0.100 \mathrm{~g}, 0.104 \mathrm{mmol})$ and THF $(10 \mathrm{~mL})$ and cooled to $0{ }^{\circ} \mathrm{C}$. Then $\mathrm{MeLi}$ (1.6 $\mathrm{M}$ in $\mathrm{Et}_{2} \mathrm{O}$, $1.35 \mathrm{~mL}, 2.16 \mathrm{mmol}$ ) was added with stirring. After $24 \mathrm{~h}$, a few drops of water were added. The solvent was removed by oil pump vacuum and the residue filtered through $\mathrm{Al}_{2} \mathrm{O}_{3}$ using $\mathrm{CH}_{2} \mathrm{Cl}_{2}$. The solvent was removed from the filtrate by oil pump vacuum to give $11 \mathrm{a}(0.095 \mathrm{~g}, 0.102 \mathrm{mmol}, 98 \%)$ as a colorless powder, mp $247{ }^{\circ} \mathrm{C}$ (capillary). DSC $\left(T_{\mathrm{i}} / T_{\mathrm{e}} / T_{\mathrm{p}} / T_{\mathrm{c}} / T_{\mathrm{f}}\right):{ }^{44} 36.6 /$ 39.0/47.0/49.8/53.5 ${ }^{\circ} \mathrm{C}$ (endotherm); 53.5/54.3/56.6/58.8/60.7 ${ }^{\circ} \mathrm{C}$ (endotherm, minor); 61.0/61.8/68.5/74.7/77.3 ${ }^{\circ} \mathrm{C}$ (endotherm, minor); 79.8/85.0/91.1/95.7/97.5 ${ }^{\circ} \mathrm{C}$ (endotherm, minor); 201.9/ 210.5/213.8/215.6/220.9 ${ }^{\circ} \mathrm{C}$ (endotherm, minor). TGA: onset of mass loss, $230.3{ }^{\circ} \mathrm{C}$. Anal. calcd (\%) for $\mathrm{C}_{46} \mathrm{H}_{90} \mathrm{O}_{2} \mathrm{P}_{2} \mathrm{Os}$ (927.38): C 59.58, H 9.78; found C 59.87, H 9.52.

\section{cis, cis,trans-Os $(\mathrm{CO})_{2}(\mathrm{Ph})_{2}\left(\mathrm{P}\left(\left(\mathrm{CH}_{2}\right)_{14}\right)_{3} \mathrm{P}\right)(12 \mathrm{a})$}

A Schlenk flask was charged with $7 \mathbf{a}(0.205 \mathrm{~g}, 0.194 \mathrm{mmol})$ and THF $(20 \mathrm{~mL})$ and cooled to $0{ }^{\circ} \mathrm{C}$. Then PhLi $\left(2.0 \mathrm{M}\right.$ in $\mathrm{Bu}_{2} \mathrm{O}$, $1.00 \mathrm{~mL}, 2.16 \mathrm{mmol}$ ) was added with stirring. The cold bath was removed. After $2 \mathrm{~h}$, the solution was refluxed. After $1 \mathrm{~h}$, a few drops of water were added. The solvents were removed by oil pump vacuum and the residue chromatographed $\left(\mathrm{SiO}_{2}\right.$ column, $2.5 \mathrm{~cm} \times 30 \mathrm{~cm}, 3: 1 \mathrm{v} / \mathrm{v}$ hexanes $/ \mathrm{CH}_{2} \mathrm{Cl}_{2}$ ). The solvents were removed from the product-containing fractions by oil pump vacuum to give $12 \mathrm{a}(0.118 \mathrm{~g}, 0.112 \mathrm{mmol}, 58 \%)$ as a colorless oil that solidified after one week, mp $162-164{ }^{\circ} \mathrm{C}$ (capillary). Anal. calcd (\%) for $\mathrm{C}_{56} \mathrm{H}_{94} \mathrm{O}_{2} \mathrm{P}_{2}$ Os (1051.52): C 63.96, H 9.01; found C 63.70, H 8.96.

\section{Acknowledgements}

We thank the US National Science Foundation (CHE-0719267, CHE-1153085), the Deutsche Forschungsgemeinschaft (DFG, GL 300/9-1), and Johnson Matthey PMC (precious metal loans) for support.

\section{Notes and references}

1 https://www.youtube.com/watch?v=YrrsSKI64vk.

2 G. S. Kottas, L. I. Clarke, D. Horinek and J. Michl, Chem. Rev., 2005, 105, 1281-1376.

3 K. Skopek, M. C. Hershberger and J. A. Gladysz, Coord. Chem. Rev., 2007, 251, 1723-1733.

4 (a) T.-A. V. Khuong, J. E. Nuñez, C. E. Godinez and M. A. Garcia-Garibay, Acc. Chem. Res., 2006, 39, 413-422; (b) C. S. Vogelsberg and M. A. Garcia-Garibay, Chem. Soc. Rev., 2012, 41, 1892-1910.

5 W. Setaka, K. Inoue, S. Higa, S. Yoshigai, H. Kono and K. Yamaguchi, J. Org. Chem., 2014, 79, 8288-8295 and earlier work from this group cited therein.

6 See also: E. Prack, C. A. O’Keefe, J. K. Moore, A. Lai, A. J. Lough, P. M. Macdonald, M. S. Conradi, R. W. Schurko and U. Fekl, J. Am. Chem. Soc., 2015, 137, 13464-13467.

7 T. Shima, F. Hampel and J. A. Gladysz, Angew. Chem., Int. Ed., 2004, 43, 5537-5540, (Angew. Chem., 2004, 116, 56535656).

8 (a) A. J. Nawara, T. Shima, F. Hampel and J. A. Gladysz, J. Am. Chem. Soc., 2006, 128, 4962-4963; (b) A. J. NawaraHultzsch, M. Stollenz, M. Barbasiewicz, S. Szafert, T. Lis, F. Hampel, N. Bhuvanesh and J. A. Gladysz, Chem. - Eur. J., 2014, 20, 4617-4637; (c) D. Taher, A. J. Nawara-Hultzsch, N. Bhuvanesh, F. Hampel and J. A. Gladysz, J. Organomet. Chem., 2016, in press.

9 L. Wang, F. Hampel and J. A. Gladysz, Angew. Chem., Int. Ed., 2006, 45, 4372-4375, (Angew. Chem., 2006, 118, 4479-4482).

10 (a) L. Wang, T. Shima, F. Hampel and J. A. Gladysz, Chem. Commun., 2006, 4075-4077; (b) A. L. Estrada, T. Jia, N. Bhuvanesh, J. Blümel and J. A. Gladysz, Eur. J. Inorg. Chem., 2015, 5318-5321.

11 G. D. Hess, F. Hampel and J. A. Gladysz, Organometallics, 2007, 26, 5129-5131.

12 See also: K. Skopek and J. A. Gladysz, J. Organomet. Chem., 2008, 693, 857-866.

13 P. D. Zeits, G. P. Rachiero, F. Hampel, J. H. Reibenspies and J. A. Gladysz, Organometallics, 2012, 31, 2854-2877.

14 T. Fiedler, Doctoral Dissertation, Universität ErlangenNürnberg, Germany, 2011.

15 (a) F. P. Dwyer and J. W. Hogarth, Inorg. Synth., 1957, 5, 206-207; (b) F. P. Dwyer and J. W. Hogarth, Inorg. Synth., 1957, 5, 204-206.

16 J. P. Collman and W. R. Roper, J. Am. Chem. Soc., 1966, 88, 3504-3508.

17 (a) In accord with protocols used earlier for similar complexes, the first cis/trans designation refers to the $\mathrm{CO}$ ligands, the second to the halide ligands, and the third to the phosphine ligands; (b) E. Lindner, H. Rothfuß, R. Fawzi and W. Hiller, Chem. Ber., 1992, 125, 541-550.

18 A. J. Nawara-Hultzsch, K. Skopek, T. Shima, M. Barbasiewicz, G. D. Hess, D. Skaper and J. A. Gladysz, Z. Naturforsch., B: Chem. Sci., 2010, 65, 414-424.

19 The reaction sequences using 1a-c were considerably slower than those using $\mathrm{PPh}_{3}$ (3-7 vs. 1-2 d), even though higher CO pressures were used (10 vs. 4-5 bar).

20 The $J$ values given for the virtual triplets represent the apparent couplings between adjacent peaks, and not the mathematically rigorous coupling constants, The indices ${ }^{n} J$ represent the number of bonds between the atom of interest and the nearest phosphorus atom. W. H. Hersh, J. Chem. Educ., 1997, 74, 1485-1488.

21 L. Song and W. C. Trogler, J. Am. Chem. Soc., 1992, 114, 3355-3361. 
22 D. E. Bergbreiter and J. M. Killough, J. Am. Chem. Soc., 1978, 100, 2126-2134.

23 (a) F. A. Cotton, N. E. Gruhn, J. Gu, P. Huang, D. L. Lichtenberger, C. A. Murillo, L. O. van Dorn and C. C. Wilkinson, Science, 2002, 298, 1971-1974; (b) F. A. Cotton, J. P. Donahue, N. E. Gruhn, D. L. Lichtenberger, C. A. Murillo, D. J. Timmons, L. O. Van Dorn, D. Villagran and X. Wang, Inorg. Chem., 2006, 45, 201-213; (c) F. A. Cotton, P. Huang, C. A. Murillo and X. Wang, Inorg. Chem. Commun., 2003, 6, 121126.

24 K. R. Laing and W. R. Roper, J. Chem. Soc., 1969, 18891891.

25 (a) R. Taube and S. Wache, J. Organomet. Chem., 1992, 428, 431-442; (b) M. Brookhart, B. Grant and A. F. Volpe, Organometallics, 1992, 11, 3920-3922.

26 D. M. Adams, Metal-Ligand and Related Vibrations, St. Martin's Press, New York, 1968, ch. 3, p. 84.

27 (a) B. F. G. Johnson and J. A. Segal, J. Chem. Soc., Dalton Trans., 1972, 1268-1271. See also: (b) D. Touchard, H. Le Bozec and P. Dixneuf, Inorg. Chim. Acta, 1979, 33, L141L142; (c) F. R. Ahmed, J. L. A. Roustan and M. Y. Al-Janabi, Inorg. Chem., 1985, 24, 2526-2532; (d) G. R. Crooks and B. F. G. Johnson, J. Chem. Soc. A, 1968, 1238-1240.

28 (a) B. F. G. Johnson and J. A. Segal, J. Chem. Soc., Dalton Trans., 1973, 478-483; (b) R. D. Wilson and J. A. Ibers, Inorg. Chem., 1979, 18, 336-343.

29 A reviewer has inquired about polymorphism. This has not yet been observed for metal containing gyroscope like complexes. However, there are several cases where two independent molecules crystallize in the unit cell (see Fig. 4 and 6 in this paper).

30 M. Stollenz, M. Barbasiewicz, A. J. Nawara-Hultzsch, T. Fiedler, R. Laddusaw, N. Bhuvanesh and J. A. Gladysz, Angew. Chem., Int. Ed., 2011, 50, 6647-6651, (Angew. Chem., 2011, 123, 6777-6781).

31 S. J. Trepanier, R. McDonald and M. Cowie, Organometallics, 2003, 22, 2638-2651.

32 (a) A. Yahav, I. Goldberg and A. Vigalok, Inorg. Chem., 2005, 44, 1547-1553; (b) A. Yahav-Levi, I. Goldberg and A. Vigalok, J. Am. Chem. Soc., 2006, 128, 8710-8711; (c) A. Yahav-Levi, I. Goldberg, A. Vigalok and A. N. Vedernikov, J. Am. Chem. Soc., 2008, 130, 724-731; (d) R. Ghosh, T. J. Emge, K. KrogJespersen and A. S. Goldman, J. Am. Chem. Soc., 2008, 130, 11317-11327.

33 A. Bondi, J. Phys. Chem., 1964, 68, 441-451.

34 When the $\left(\mathrm{CH}_{2}\right)_{m} \mathrm{CH}=\mathrm{CH}_{2}$ substituted phosphine ligands in VIII $\left(\mathrm{MX}_{2}=\mathrm{PtCl}_{2}\right)$ are replaced by tribenzylphoshine ligands that contain ortho $\mathrm{O}\left(\mathrm{CH}_{2}\right)_{4} \mathrm{CH}=\mathrm{CH}_{2}$ substituents, only the mixed intra/interligand metathesis mode is observed: J. Han, C. Deng, R. Fang, D. Zhao, L. Wang and J. A. Gladysz, Organometallics, 2010, 29, 3231-3234.

35 K. Aoki, M. Kudo and N. Tamaoki, Org. Lett., 2004, 4009-4012. 36 V. R. Thalladi, M. Nüsse and R. Boese, J. Am. Chem. Soc., 2000, 122, 9227-9236.

37 (a) J. C. Conrad, M. D. Eelman, J. A. Duarte Silva, S. Monfette, H. H. Parnas, J. L. Snelgrove and D. E. Fogg, J. Am. Chem. Soc., 2007, 129, 1024-1025; (b) S. Monfette and D. E. Fogg, Chem. Rev., 2009, 109, 3783-3816.

38 (a) E. V. Ansyln and D. A. Dougherty, Modern Physical Organic Chemistry, University Science Books, Sausalito, California, 2006, pp. 97-98; (b) E. N. Eliel and S. H. Wilen, Stereochemistry of Organic Compounds, Wiley, New York, 1994, pp. 624-629 and 1142-1155.

39 For reference molecules, see: (a) J. K. Stalick and J. A. Ibers, Inorg. Chem., 1969, 8, 419-423; (b) P. D. Robinson, C. C. Hinckley and A. Ikuo, Acta Crystallogr., Sect. C: Cryst. Struct. Commun., 1988, 44, 1491-1492; (c) M. A. Esteruelas, F. J. Lahoz, J. A. Lopez, L. A. Oro, C. Schlünken, C. Valero and H. Werner, Organometallics, 1992, 11, 2034-2043; (d) G. Bellachioma, G. Cardaci and P. Zanazzi, Inorg. Chem., 1993, 32, 547-553; (e) K. S. Coleman, J. Fawcett, J. H. Holloway, E. G. Hope and D. R. Russell, J. Chem. Soc., Dalton Trans., 1997, 3557-3562; $(f)$ M. L. Buil, M. A. Esteruelas, E. Oñate and N. Ruiz, Organometallics, 1998, 17, 3346-3355; (g) H. C. S. Clark, K. S. Coleman, J. Fawcett, J. H. Holloway, E. G. Hope, J. Redding and D. R. Russell, Polyhedron, 1999, 18, 1207-1210.

40 G. M. Lang, Doctoral Thesis, Texas A\&M University, 2016.

41 G. M. Lang, D. Skaper, F. Hampel and J. A. Gladysz, manuscript in preparation.

42 (a) V. Bermudez, N. Capron, T. Gase, F. G. Gatti, F. Kajzar, D. A. Leigh, F. Zerbetto and S. Zhang, Nature, 2000, 406, 608-611; (b) R. D. Horansky, L. I. Clarke, J. C. Price, T.-A. V. Khuong, P. D. Jarowski and M. A. Garcia-Garibay, Phys. Rev. B: Condens. Matter, 2005, 72, 014302; (c) R. D. Horansky, L. I. Clarke, E. B. Winston, J. C. Price, S. D. Karlen, P. D. Jarowski, R. Santillan and M. A. Garcia-Garibay, Phys. Rev. B: Condens. Matter, 2006, 74, 054306; (d) P. Dhar, C. D. Swayne, T. M. Fischer, T. Kline and A. Sen, Nano Lett., 2007, 7, 1010-1012; (e) J. J. Arcenegui, P. García-Sánchez, H. Morgan and A. Ramos, Phys. Rev. E: Stat. Phys., Plasmas, Fluids, Relat. Interdiscip. Top., 2013, 88, 033025.

43 The sample gradually darkened without melting above this temperature.

44 DSC and TGA data were treated as recommended by H. K. Cammenga and M. Epple, Angew. Chem., Int. Ed., 1995, 34, 1171-1187, (Angew. Chem., 1995, 107, 1284-1301). The $\mathrm{T}_{\mathrm{e}}$ values best represent the temperature of the phase transition or exotherm. 